Review

\title{
Application of Pharmacokinetic and Pharmacodynamic Analysis to the Development of Liposomal Formulations for Oncology
}

\author{
Sihem Ait-Oudhia ${ }^{1, *}$, Donald E. Mager ${ }^{1}$ and Robert M. Straubinger ${ }^{1,2}$ \\ 1 Department of Pharmaceutical Sciences, University at Buffalo, State University of New York, \\ Amherst, NY 14214, USA; E-Mails: dmager@buffalo.edu (D.E.M.); rms@buffalo.edu (R.M.S.) \\ 2 Departments of Cancer Pharmacology and Therapeutics, and Molecular and Cellular Biophysics \\ and Biochemistry, Roswell Park Cancer Institute, Elm/Carton Streets, Buffalo, NY 14263, USA \\ * Author to whom correspondence should be addressed; E-Mail: Sihema@buffalo.edu; \\ Tel.: +1-716-645-4809; Fax: +1-716-829-6965.
}

Received: 14 January 2014; in revised form: 22 February 2014 / Accepted: 26 February 2014 / Published: 18 March 2014

\begin{abstract}
Liposomal formulations of anticancer agents have been developed to prolong drug circulating lifetime, enhance anti-tumor efficacy by increasing tumor drug deposition, and reduce drug toxicity by avoiding critical normal tissues. Despite the clinical approval of numerous liposome-based chemotherapeutics, challenges remain in the development and clinical deployment of micro- and nano-particulate formulations, as well as combining these novel agents with conventional drugs and standard-of-care therapies. Factors requiring optimization include control of drug biodistribution, release rates of the encapsulated drug, and uptake by target cells. Quantitative mathematical modeling of formulation performance can provide an important tool for understanding drug transport, uptake, and disposition processes, as well as their role in therapeutic outcomes. This review identifies several relevant pharmacokinetic/pharmacodynamic models that incorporate key physical, biochemical, and physiological processes involved in delivery of oncology drugs by liposomal formulations. They capture observed data, lend insight into factors determining overall antitumor response, and in some cases, predict conditions for optimizing chemotherapy combinations that include nanoparticulate drug carriers.
\end{abstract}

Keywords: liposomes; nanoparticulate drug carriers; drug delivery; pharmacokinetics; pharmacodynamics; mathematical simulation 


\section{Introduction}

In the 1960s it was observed that purified phospholipids from biological sources spontaneously form closed vesicular structures when hydrated. Since that seminal discovery, a sustained effort has been devoted to the development of lipid vesicles (liposomes) as a drug delivery system for numerous applications, including cancer therapy [1,2]. Structurally, liposomes are microscopic vesicles that enclose an internal aqueous space within one or more bilayer membranes composed of natural or synthetic phospholipids. They are biocompatible and biodegradable, generally low in toxicity, and seldom immunogenic. A variety of approaches permit control of particle size, and the smallest liposomes qualify as nanoparticulate drug carriers.

Figure 1 depicts schematically the numerous physicochemical characteristics and modifications that have been employed to optimize the liposome carrier for different applications [3,4]. The limiting phospholipid bilayer membrane surrounds an internal aqueous space that can be used to encapsulate hydrophilic chemotherapeutic drugs, whereas hydrophobic agents can be accommodated by incorporation into the membrane [3,5]. The bilayer membrane can include components that provide physicochemical control over pharmacokinetic (PK) properties such as elimination half-life, biodistribution, permeability, and drug release rate. In addition to the membrane physicochemical properties that affect drug release rate and PK, which will be discussed below, the external surface of the liposome can be modified in several ways that can alter biodistribution significantly: (i) glycolipids or synthetic hydrophilic polymers such as polyethylene glycol (PEG) covalently bound to the membrane can produce sterically stabilized liposomes (SSL), which have reduced opsonization and extended circulating plasma half-life; (ii) the surface can be decorated covalently with targeting ligands that enhance binding and internalization by cancer cells expressing a receptor for the ligand, such as immunoglobulins or their subunits (e.g., immunoglobulin fragment antigen binding (Fab'); and single-chain variable fragments, $\mathrm{scFv}$ ), or nutrient molecules having affinity for cell surface receptors (e.g., transferrin; folate); and (iii) engineered for triggered release of the encapsulated drug at the tumor site, which can be achieved by sensitizing the bilayer membrane to a specific stimuli such $\mathrm{pH}$, light, oxidation, enzymatic degradation, heat, or radiation [6,7]. As an example, through mild hyperthermia $\left(41{ }^{\circ} \mathrm{C}\right)$, liposomal doxorubicin (L-DXR) showed an improvement in the tumor vasculature permeability, a subsequent increase in liposome extravasation, and an enhanced interstitial penetration $[8,9]$.

Numerous liposome-based products have been approved or marketed [10]. For oncology applications, several classes of antineoplastic agents have been incorporated into liposomes in order to increase their therapeutic index. They include taxanes [11-13], anthracyclines [14,15], platinum analogs [16,17], camptothecins [18-21], Vinca alkaloids [22,23], and antimetabolites [24]. Numerous liposomal anticancer drugs are in late stage clinical development or are clinically approved. A selection is shown in Table 1. Food and Drug Administration (FDA) approved products include conventional- and SSL-based formulations of doxorubicin (Myocet ${ }^{\circledR}$ and Doxil ${ }^{\circledR}$ ), daunorubicin $\left(\right.$ DaunoXome $^{\circledR}$ ), vincristine (Marqibo ${ }^{\circledR}$ ), and cytarabine (DepoCyte ${ }^{\circledR}$ ). 
Figure 1. Schematic representation of four categories of drug-loaded liposomes. The liposome consists of a bilayer phospholipid membrane surrounding an internal aqueous core. Drugs may be incorporated in either compartment, depending on their partition coefficient. The surface of the prototype liposome is unmodified, and its charge reflects the molar ratio of neutral or negatively charged phospholipids. The bilayer may be modified to display (i) polymers such as polyethylene glycol (PEG) on the surface to prolong the plasma circulation time (sterically stabilized liposomes); (ii) immunoglobulins or immunoglobulin fragment antigen binding (Fab') to target specific antigens or receptors (immunoliposomes); or (iii) positive charge (cationic liposomes). Adapted with permission from [25]. Copyright 2014 Elsevier.

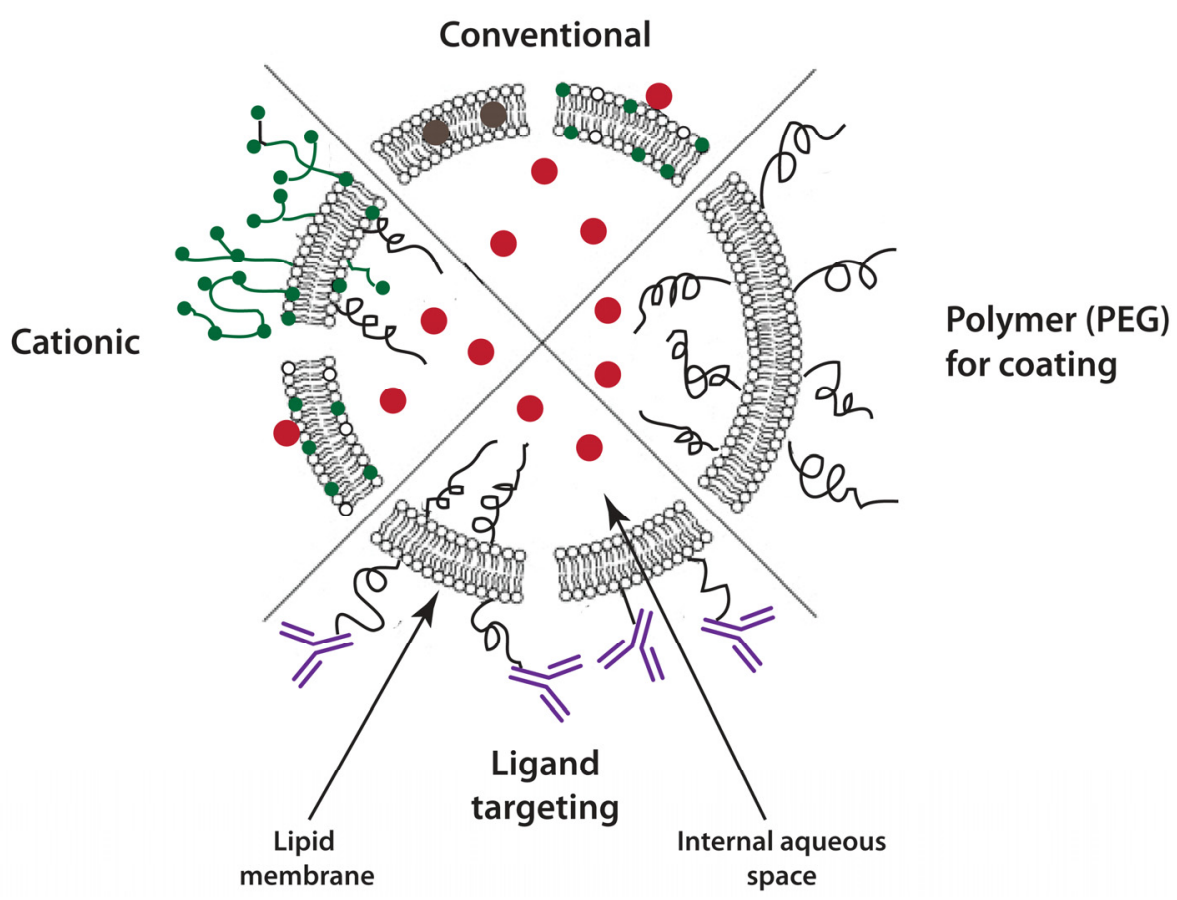

In some cases, liposome incorporation can increase the antitumor efficacy of the encapsulated drugs by providing more selective delivery or targeting to the tumor tissue, whereas in other cases, toxicity is reduced by avoidance of critical normal tissues. Ultimately, modulation of the pharmacokinetic and pharmacodynamic (PD) properties of cytotoxic drugs is responsible for improving their overall pharmacological properties. Examples of beneficial pharmacokinetic effects mediated by liposomes include: reducing metabolism or inactivation of labile drugs in the plasma or tissues; extending drug circulating half-life by reducing drug removal (clearance) from the blood; decreasing drug distribution to healthy tissues because of the particle size limitation for transport across healthy vascular endothelium; and increasing the fraction of the injected dose delivered to the tumor site because of flaws in the tumor vascular endothelium, which underlies the extended permeability and retention (EPR) of nanoparticulates in the tumor interstitium [3,26]. Examples of beneficial pharmacodynamic effects mediated by liposomes are more elusive to identify; alterations of PD would manifest themselves following careful analysis and accounting for PK effects on drug biodistribution at the organismal, tissue, and cellular levels. It is likely that the source of most apparent changes in PD, such as an increase in potency of an encapsulated drug relative to the unencapsulated drug, actually arise 
from biodistributional (PK) effects such as demonstrated for the gemcitabine-loaded innovative nanocarrier formulation [27]

Table 1. Available liposomal drugs in oncology.

\begin{tabular}{|c|c|c|c|}
\hline \multicolumn{4}{|c|}{ Approved liposomal anticancer chemotherapeutics } \\
\hline Liposomal anticancer drug & Brand name & Indications & References \\
\hline \multirow[t]{4}{*}{ Pegylated liposomal DXR } & Doxil $^{\circledR}$ & AIDS-related Kaposi's sarcoma & {$[28-30]$} \\
\hline & & Metastatic ovarian cancer & \\
\hline & & Metastatic breast cancer & [31-34] \\
\hline & & Multiple myeloma & [35-38] \\
\hline Non-pegylated liposomal DXR & Myocet $^{\mathbb{R}}$ & Same indications as Doxil ${ }^{\circledR}$ & [39-41] \\
\hline Liposomal daunorubicin & DaunoXome ${ }^{\circledR}$ & AIDS-related Kaposi's sarcoma & {$[42]$} \\
\hline \multirow[t]{2}{*}{ Liposomal cytarabine } & & Acute myeloid leukemia & [43] \\
\hline & DepoCyte $^{\circledR}$ & $\begin{array}{l}\text { Lymphomas and leukemia with } \\
\text { meningeal spread }\end{array}$ & [44] \\
\hline \multicolumn{4}{|c|}{ Liposomal anticancer drugs in development } \\
\hline Drug name & Encapsulated drug & Stage of development & References \\
\hline Liposomal annamycin & Annamycin & Phase II & {$[45,46]$} \\
\hline SPI-77 & Cisplatin & Phase II & {$[16,47-49]$} \\
\hline Lipoplatin & Cisplatin & Phase III & [50] \\
\hline LiPlaCis & Cisplatin & Phase I & [51] \\
\hline L-NDDP/aroplatin & Cisplatin analogue & Phase II & {$[17,52]$} \\
\hline ThermoDox $^{\circledR}$ & Doxorubicin & Phase II & [53] \\
\hline JNS002 & Doxorubicin & Phase II & [54] \\
\hline TLI & Topotecan & Trial & www.clinicaltrials.gov \\
\hline OSI211 & Lurtotecan & Phase III & {$[52,55]$} \\
\hline LEM & Mitoxantrone & Preclinical & [56] \\
\hline NL CPT-11 & Camptothecin & Trial & www.clinicaltrials.gov \\
\hline L9NC & 9-Nitro-20-(S)-camptothecin & Trial & www.clinicaltrials.gov \\
\hline PNU-93914 & Paclitaxel & Trial & www.clinicaltrials.gov \\
\hline LEP-ETU & Paclitaxel & Trial & www.clinicaltrials.gov \\
\hline IHL-305 & Irinotecan & Phase I & [57] \\
\hline PEP02 & Irinotecan & Phase I & [58] \\
\hline MBP426 & Oxaliplatin & Phase I & [59] \\
\hline LE-SN38 & Active metabolite of Irinotecan & Trial & www.clinicaltrials.gov \\
\hline Marqibo $^{\circledR}$ & Vinscristine & Phase II & {$[60]$} \\
\hline VLI & Vinorelbine & Trial & www.clinicaltrials.gov \\
\hline CPX-1 & $\begin{array}{l}\text { Combination: Irinotecan }+ \\
\text { Floxuridine }\end{array}$ & Phase I & [61] \\
\hline CPX-351 & $\begin{array}{l}\text { Combination: Cytarabine + } \\
\text { Daunorubicin }\end{array}$ & Phase I & [62] \\
\hline
\end{tabular}


The development of liposome-based formulations involves optimization of a considerable number of parameters that ultimately impact therapeutic performance. Although many guiding principles are known, optimization remains largely empirical. A quantitative basis by which to rationalize or anticipate the impact of changes in the myriad factors controlling therapeutic efficacy is almost entirely lacking. New strategies are required to overcome these challenges; one consists of developing in silico approaches, such as mathematical modeling, to identify experimentally testable hypotheses that explain how carrier-based formulations can improve PK characteristics, and describe quantitatively the pharmacological action of carrier-associated anticancer drugs. Advanced PK and PD modeling may aid in the optimization of liposome design parameters, such as PK/disposition, drug release rate, and cellular uptake, thus maximizing the delivery of encapsulated drugs at the site of the tumor.

The objective of this work is to articulate a role for mathematical modeling as a tool to: (i) identify and characterize quantitatively the key determinants and processes that dictate the PK and antitumor activity of liposomal formulations; (ii) streamline the development of optimized liposomal formulations; and (iii) aid in the rational development of therapies that combine conventional oncology drugs with nanoparticulate-embodied agents. The principle physicochemical and functional properties of the drug/liposome carrier complex that influence PK and biodisposition most heavily will be explored. Examples will be identified in the literature in which PK/PD models contributed to the understanding of performance-determining characteristics of liposomal anticancer agents and their optimization. Finally, multi-scale systems analysis approaches will be highlighted that seek to bridge quantitatively from preclinical models to human clinical application, and reveal the role of tumor- and drug-carrier system parameters that control tumor drug delivery.

\section{Requisite Drug and Carrier Properties}

The effectiveness of liposomes as oncology drug carriers depends on a balance among numerous factors, such as stability in the circulation, ability to access the target site, and ability to release the drug at the site of action in the tumor. Multiple criteria must be considered in matching properties of the drug with those of the liposome carrier.

First, the drug must demonstrate activity against the chosen tumor type. Common examples include anthracyclines and Vinca alkaloids, which have shown activity against a broad range of cancers $[14,15,22,23,63]$.

Second, the loading of the drug in the liposome carrier must be both adequate and, for commercial viability, efficient. Sufficient drug must be incorporated in the carrier to permit delivery of a pharmacologically active dose with an acceptable amount of carrier lipids. The use of active loading techniques increases both cargo capacity and efficiency of encapsulation. An example is the strategy of employing $\mathrm{pH}$ and/or electrochemical gradients coupled with a trapping agent within the liposome interior, which can raise encapsulation efficiency for amphipathic basic amines such as DXR or vinblastine to essentially 100\%, with high drug:lipid loadings [64-70].

Third, the drug must be transported stably by the carrier in the circulation yet be released from the carrier at the tumor site with the appropriate rate. The physicochemical properties of the chemotherapeutic agent to be incorporated into the carrier play an important role in determining its release rate. 
Candidate drugs can be classified into three categories based on their hydrophobic properties, as reflected in their octanol:water partition coefficient $\left(K_{\mathrm{p}}\right)$ : (i) highly hydrophilic drugs $\left(K_{\mathrm{p}}<1\right)$; (ii) highly hydrophobic drugs $\left(K_{\mathrm{p}}>3\right)$; and (iii) amphipathic drugs of intermediate $K_{\mathrm{p}}$. Examples of the first category include cytosine arabinoside, cisplatin, methotrexate and $N$-(phosphonacetyl)-L-aspartate. Liposomal formulations designed with these types of drugs may have low capture efficiency if passive encapsulation is employed. Such formulations may be highly stable in vivo with the appropriate liposome composition, and release rates may require optimization to provide the appropriate bioavailability at the tumor site. Some strategies to control drug release rates revolve around designing carriers that are stable in plasma but rapidly destabilized in the tumor to facilitate the delivery of free drug.

The second category of drugs tends to intercalate into the liposome bilayer, improving their overall solubility and often their biodistribution, but rendering the drugs prone to rapid extraction or exchange with plasma proteins after administration. These drugs may not be appropriate for active targeting strategies if the release rate is high.

The third category of drugs would also have relatively rapid release rates because their intermediate partition coefficients confer moderate water solubility and membrane permeability. However, in combination with loading methods that entrap drugs stably in the liposome interior, they may be highly suitable for liposome-based delivery. This group of agents includes somewhat lipophilic cationic drugs such as the anthracyclines (DXR, daunorubicin), anthracenediones (mitoxantrone), Vinca alkaloids (vincristine, vinblastine, and vinorelbine), camptothecins, and numerous others. With this drug category, it is possible to modulate the drug-release rates by employing gradient-based loading techniques in order to maintain stable encapsulation in the circulation, yet allow the drug to be released at the tumor site $[14,65,66,68,71-74]$.

\section{Integration of in Vivo Factors Influencing Pharmacokinetic (PK) and Performance of Liposomal Formulations}

The interaction of liposomes with in vivo systems is enormously complex and involves many factors that affect therapeutic performance. Total systemic clearance is often regarded as the most important global pharmacokinetic property owing to its inverse relationship with net drug exposure and the average steady-state plasma concentration achieved during continuous administration. Net drug exposure is the area under the drug concentration-time curve (AUC). Continuous administration can include both constant-rate of infusion and/or multiple-dosing regimens. The overall clearance of liposomal formulations is dependent upon three factors: (i) the rate of elimination of the liposome carrier itself; (ii) the rate of release of the encapsulated or membrane-incorporated drug from the carrier; and (iii) the rate of elimination and metabolism of released drug that is no longer associated with the carrier.

The processes by which liposomes and other nanoparticles are cleared from the bloodstream have been investigated in considerable detail $[75,76]$. The main mechanism for their elimination is through recognition and uptake by macrophages of the reticuloendothelial system (RES), which reside primarily within the liver and spleen [77-80]. Liposome clearance may be influenced by physicochemical factors that are discussed below, including the vesicle size, lipid composition of the membrane, and release rate of liposome contents. Liposomes can also interact with plasma constituents such as 
proteins, thus affecting their fate in vivo, either by affecting their stability and/or modulating their subsequent interaction with the target cells [75]. Plasma protein interactions may extract or exchange lipids from the carrier, compromising its integrity. Mediators of clearance include plasma protein opsonins, fibronectin, C-reactive protein (CRP), the C3b complement fragment, $\beta 2$-glycoprotein I, or the Fc portion of an immunoglobulin $\mathrm{G}(\mathrm{IgG})$ [77,81,82]. Opsonization can compromise liposome stability and promote endocytosis or phagocytosis by macrophages of the RES. Renal excretion may represent a significant component of total clearance for very small nanoparticles $(<4-8 \mathrm{~nm}$ diameter $)$ but does not impact clearance of most liposome formulations (>30 nm) $[83,84]$.

The stability of drug association with the liposome has the potential to alter substantially the circulation half-life and other pharmacokinetic properties of the drug, depending upon the relative magnitude of differences in the factors controlling drug and liposome disposition. Efforts to promote the internalization of drug-loaded liposomes by cancer cells can raise efficacy (below), but local release of drug from extracellular liposomes can provide the main component of therapeutic efficacy in some applications. For these reasons, drug release from liposomes has major impact upon toxicity and antitumor efficacy $[3,85]$. A number of studies identify the kinetic complexities arising from the rate of tumor accumulation of liposomes and the rate of drug release, and show that it may be necessary to modulate the rate of drug release for optimal efficacy $[71,74,86]$. Measurement of in vivo drug release rate is enormously important in the development of liposome formulations but can be highly challenging for certain types of drugs. Total plasma concentration usually can be quantified by conventional technologies. Released drug has been measured directly by numerous methods including microdialysis or solid-phase micro-extraction techniques [87,88], both of which are tedious and expensive. Indirect approaches for measuring in vivo drug release rates include simply measuring changes in the plasma drug-to-liposome ratio [21,89], which is valid for cases in which the clearance rate of the released drug from plasma is sufficiently faster than the release rate from liposomes. For hydrophobic drugs, or drugs having a high fraction of plasma protein binding, measurement of released drug can be exquisitely challenging, but nonetheless an extraordinarily important component for understanding the parameters affecting dosage form performance. In the absence of measured drug release kinetics, strategies employing modeling of pharmacokinetic profiles for liposomal- and unencapsulated drug may provide indirect in vivo estimates of the drug release rates. One recently described indirect approach permitted inference of drug release rates based upon measurements of the free fraction of drug in plasma (i.e., the fraction of released drug unbound by plasma proteins) [90], which was employed successful in a PK modeling application for a nanoemulsion paclitaxel formulation. A second approach employed simple compartmental modeling of liposomal- and unencapsulated amphotericin B PK to estimate a single, species-independent first-order release rate constant for rats and humans [91].

The accumulation of liposomes in tumors is controlled by numerous processes, including tumor perfusion, extravasation into the tumor tissue, and transport within the interstitium [92,93]. The permeability of the tumor microvasculature governs the influx and efflux of drugs [92,94-97]. Most liposome deposition results from the EPR effect [26], in which the discontinuous, permeable tumor vascular endothelium, and impaired lymphatics surrounding the tumor [26,98-101], permit extravasation and accumulation. Drug exposure to healthy tissues (and associated toxicities) is limited by the integrity of the normal tissue vasculature to nanoparticulates. Compared to extravasation via the 
discontinuous endothelium of the tumor microvasculature, transcytosis of liposomes through vascular endothelial cells is thought to represent a relatively minor pathway. High tumor interstitial fluid pressure also limits liposome diffusion into tumors.

Once in the tumor, most liposome compositions tend to remain in close proximity to the microvessels from which they extravasated because of the high tumor interstitial pressure, the dense extracellular tissue stromal matrix, a large interstitial space compared with normal tissues, and the low diffusion coefficient of nanoparticulates [93,95-97,99,101]. The high interstitial pressure of larger tumors has been reported to reduce liposome distribution into the tumor interstitium in comparison to smaller tumors, and, as expected for regions of tumor into which oxygen and nutrients do not readily penetrate, there is little liposome penetration into necrotic regions of tumors [95].

The intracellular delivery of encapsulated drugs appears to enhance the efficacy of numerous agents. It is generally accepted that the majority of liposomes enter cells through the endocytic pathway, which is supported by both direct and functional evidence [102-106]. However, the molecular mechanisms of cellular binding and internalization of liposomes are not yet fully understood. If targeting cell surface receptors that are endocytosed can enhance intracellular delivery, tumor cell killing and antitumor efficacy can be increased [107-110]. Intracellular release of drug from the endocytic compartment is a necessity, and various approaches to enhance release to the cytoplasm have been investigated. One involves $\mathrm{pH}$-triggered strategies that exploit the acidic tumor microenvironment or acidic endosomal compartments to destabilize liposomes [111-113]. Another example employs the selection of agents that require a liposome carrier for optimal delivery to the endocytic compartment; such "liposome dependent drugs" are polar, weakly acidic drugs that become more membrane permeable at endosomal and lysosomal $\mathrm{pH}[105,106,114]$.

\section{Physicochemical Properties of Liposomal Formulations and Their Effects upon Pharmacokinetics}

Numerous physicochemical properties of liposomes influence their pharmacokinetics directly or indirectly, and are discussed below.

\subsection{Particle Size}

In general, the clearance of liposomes and other nano- or micro-particulates from the blood increases with increasing particle size [85,115,116], and clearance is mediated principally by the RES. Smaller liposomes tend to have longer circulation half-lives than larger liposomes of the same membrane composition, and distribute more rapidly in solid tumors due to their enhanced ability to extravasate across the more porous tumor endothelia [85,116]. It has been suggested that despite their slower clearance from the circulation, smaller liposomes $(60-80 \mathrm{~nm})$ tend to accumulate in tumors less efficiently than slightly larger liposomes $[115,116]$. Thus the longer circulating lifetime of the smallest liposomes may be counter-balanced by an increase in reversible permeability (enhanced influx and efflux rate constants), and therefore the role of diameter in optimizing liposome deposition may depend upon an interplay with additional variables. Liposomes of approximately $100 \mathrm{~nm}$ diameter have been reported to distribute into solid tumors with an efficiency that is partly dependent on the anatomical location of the tumor [117]. 
Liposome surface properties modulate the degree to which liposome size influences total blood clearance. Clearance of sterically stabilized liposomes of relatively large diameters (80-250 nm), such as SSL that bear a polyethylene glycol corona on their surface, is less sensitive to the effects of particle size than is clearance of non-pegylated liposomes of equivalent size [118,119]. Naturally occurring glycolipids and glycophospholipids can exert similar effects [120,121]. Maximum accumulation of sterically-stabilized liposomes in xenograft animal models typically occurs between 24 and 48 h post administration $[96,108,120]$.

\subsection{Membrane Charge}

The incorporation of high molar ratios of charged lipids accelerates the clearance of liposomes. Negatively charged liposomes commonly include anionic phospholipids such as phosphatidic acid (PA), phosphatidylserine (PS), and phosphatidylglycerol (PG). Positively charged liposomes are commonly composed of cationic dialkyl/diacyl lipids such as dioleoyl-trimethylammonium-propane (DOTAP), di-octadecenyl-trimethylammonium-propane (DOTMA) and other analogs. Stearylamine has been used historically as a constituent of cationic liposomes, but is more cytotoxic than dialkyl or diacyl lipids, and more likely to undergo extraction from the membrane or inter-membrane exchange [122-124].

Negatively charged liposomes tend to be removed from circulation by the macrophages of the RES, and increasing charge increases total systemic clearance [77,125]. A notable exception is the anionic glycerophospholipid phosphatidylinositol (PI), which can mediate a longer circulating lifetime because of the "steric stabilization" effect of its inositol headgroup [96,119,120]. Positively charged liposomes are cleared rapidly by the RES, but also bind rapidly to vascular endothelium, sites of inflammation, and plasma proteins [126-128].

\subsection{Membrane Lipid Composition and Surface Properties}

The combination and physicochemical characteristics of lipids from which liposomes are prepared are critical in influencing the pharmacokinetics of the carrier and the associated drug. Liposome physicochemical properties can influence total drug clearance in several ways. The first is by modulating directly the rate of liposome recognition and elimination by cellular clearance mechanisms and tissues of the RES. The second is by modulating the release rate of drug from the carrier, which results in pharmacokinetics that reflect the circulating life-time of the free drug; small-molecule drugs tend to be cleared relatively rapid compared to liposomes that have been optimized for extended circulation times. Both drug release and liposome clearance by the RES are reduced by employing high phase-transition (high $\mathrm{T}_{\mathrm{m}}$ ) phospholipids such as distearoyl or hydrogenated phosphatidylcholines (PC), and the inclusion of cholesterol (Chol): decreased binding of plasma opsonins reduces RES clearance through receptor-mediated pathways, and a reduced ability of proteins to insert into cholesterol-rich, high $\mathrm{T}_{\mathrm{m}}$ membranes reduces drug leakage [77,129,130]. Sphingomyelin (SM) also can exert a stabilizing effect on the phospholipid bilayer, and the combination of SM/Chol has been reported to extend the circulation lifetime of liposome-encapsulated drugs compared to the same drugs in distearoyl-phosphatidylcholine (DSPC)/Chol liposomes [131]. Surface modifications that sterically stabilize liposomes and extend circulating lifetime have been described above. 


\subsection{Operational Categorization of Liposomes}

The wide range of liposome characteristics and performance that can be produced by blending these and additional properties is a considerable advantage of this carrier system. Conceptually there may be several operational categories of liposomes based on composition and in vivo utilization (Figure 1). This grouping is not exclusive or absolute.

\subsubsection{Conventional Liposomes}

First-generation liposomes developed as a drug carrier system fall into this category. Composed of charge-neutral and/or negatively charged phospholipids, such liposomes typically have short blood circulation times. After intravenous administration, these liposomes undergo protein binding and insertion, phospholipid exchange, opsonization, rapid uptake by macrophages, and accumulation in tissues of the RES. Rapid clearance and low stability of encapsulation can limit seriously their application for the treatment of many diseases. Exceptions exist; one is that such liposomes may be effective for increasing the apparent solubility of highly lipophilic drugs; a second is where delivery to macrophages or to the RES is an application, for example, where the objective is delivery of immunomodulators to macrophages in order to enhance their capability to kill neoplastic cells [132].

\subsubsection{Sterically-Stabilized Liposomes (SSL)}

The development of long-circulating liposomes represents a significant advance in liposomal drug carriers [133]. The advantage of SSL is their ability to extravasate into solid tumors due to the EPR effect. As described above, a variety of covalently-linked, hydrated, surface-modifying groups delays clearance by the RES and results in prolonged circulation times ( $\geq 24-48 \mathrm{~h}$ ).

\subsubsection{Immunoliposomes}

Receptor-specific ligands, typically immunoglobulins or their subunits, have been investigated as a means to promote tumor deposition as well as tumor cell uptake of liposomes. A growing consensus suggests that the magnitude of tumor deposition attributable to the EPR effect may be greater than the contribution of ligand-based arrest within the tumor, and that the major advantage of the targeting ligand is to promote liposome endocytosis and intracellular delivery [108,134-140]. The necessity for the drug to escape the endocytic pathway suggests an advantage of the enhanced permeability of "liposome-dependent" drugs [105,106,114], many of which are weakly acidic and would be more permeant at acidic $\mathrm{pH}$ of endosomes/lysosomes. However, weakly basic drugs such as the anthracyclines and Vinca alkaloids have been used quite successfully in endocytosis-prone liposomes, despite the fact that they would be less membrane permeant at acidic $\mathrm{pH}$. Ligand-targeted liposomes, being highly multivalent, show much higher affinities for target cells than do the individual ligands [141]. A recent example demonstrated that the anticancer activity of human epidermal growth factor receptor 2 (HER2)-targeted immunoliposomes is relatively independent of the intrinsic affinity of the receptor for its cognate ligand: despite relatively low binding affinity of the targeting ligand $\left(k_{\mathrm{D}}=160 \mathrm{nM}\right)$, the targeted liposome construct showed improved efficacy as a result of its efficient internalization [137]. 


\subsubsection{Cationic Liposomes}

The initial development of these liposomes was focused on delivery of complexed nucleic acids to the cell interior, thus promoting delivery and expression of these large, highly hydrophilic, negatively-charged molecules. Because of the propensity of cationic liposomes to bind to vascular endothelium and sites of inflammation (above) they may have additional applications in oncology drug delivery.

\section{PK/ Pharmacodynamic (PD) Analysis of Liposomal Formulations}

Unmodified first-generation liposomes typically exhibit nonlinear, saturable PK after intravenous administration, with relatively short elimination half-lives at low, non-saturating doses [142]. Although sterically-stabilized liposomes may show linear PK over a wide range of doses [142], their PK and biodistributional pattern is also complicated at low doses and upon repeated administration schedules [143-148]. It is hypothesized that at lower doses, the differences in plasma half-lives between conventional liposomes and SSL should result in a greater pool of SSL available for tumor deposition. For higher doses, the saturable elimination processes for conventional liposomes should be at-capacity, and therefore differences in clearance and tumor deposition among various liposome types should be reduced. The factors modulating the PK behavior of drugs in conventional liposomes and SSL include physicochemical properties of the liposomal carrier as discussed above, the dose, dosing schedule, the route of administration, the specific drug that is encapsulated, as well as the presence of targeting ligands or other surface-displayed molecules, all of which can affect the PK of the liposomal carrier or retention of the drug.

\subsection{Mathematical Modeling of Liposomal Anticancer Drugs}

The PK of SSL formulations of DXR are clearly distinct from that of unencapsulated DXR [149]. The SSL formulation has an extended circulating lifetime and a pattern of tumor- and tissue distribution that reduces drug deposition in heart, a major organ of DXR toxicity; it also increases deposition in skin [115], which appears to correlate with a novel adverse effect of SSL-DXR [150,151].

Arnold et al developed a simple PK model for brain tumor deposition of SSL-DXR in rats [152], which consisted of a one-compartment model having linear elimination from the plasma that was linked to a peripheral compartment representing the site of action (i.e., the brain tumor). The context for development of the model was to understand why specifically-timed dosing schemes with SSL-DXR mediated a progressive increase in brain tumor vascular permeability, and resulted in elevated deposition of subsequent SSL-DXR doses [144]. The objective was to identify quantitatively the pharmacokinetic factors that might underlie the elevated deposition of subsequent doses in this "tumor priming" administration schedule. Therefore, the model included explicit tumor influx- and efflux rate constants for unencapsulated DXR and SSL-DXR. The final model reasonably captured plasma and brain tumor concentration-time profiles of DXR for both formulations, and for single- and multiple-dosing schemes. The analysis supported the conclusion that in rats administered a dose of SSL-DXR one week previously, intratumor DXR concentrations increased more rapidly, and to a greater extent, compared to naïve (previously-untreated) animals. The model estimated that the prior 
SSL-DXR treatment elevated tumor vascular permeability and increased the SSL-DXR influx rate 4 -fold, whereas the efflux rate increased by 2 -fold. The net result was an overall increase in tumor drug deposition that agreed well with experimental data. The model also captured an observed shift in the peak time of SSL-DXR accumulation to earlier time points, consistent with elevated tumor vascular permeability. Although deposition in the brain tumor as well as elimination processes were relatively well described, the model did not distinguish between the delivery of liposome-encapsulated drug and liposome-released drug. Nor did it account for the release kinetics of DXR from the liposome.

A subsequently developed PK model for SSL-DXR (Figure 2) [153] included estimates of drug release rate along with tumor drug delivery. It was developed in the context of understanding PK/PD relationships for SSL-DXR in a "tumor priming" combination strategy, in which a prior dose of paclitaxel increased tumor permeability, as well as deposition and intra-tumor diffusion of SSL-DXR [154]. Data for tumor deposition that discriminated liposome-encapsulated vs. released DXR were not available. Therefore, the model assumed, as a simplification, that the release of DXR from liposomes to the plasma is governed by a linear first-order process. Once in the plasma, free drug could undergo linear clearance, distribute into a peripheral systemic compartment, or partition into a tumor compartment. In the tumor compartment, SSL-DXR concentrations were defined by a well-stirred model. The final model not only captured the data well, but also estimated the half-life of DXR release from liposomes to be approximately $15 \mathrm{~h}$ (first order release constant $k_{\text {rel }}=0.046$ ), which is consistent with other studies of in vitro and in vivo drug release rates for similar liposome formulations $[71,155]$.

Another approach to characterizing PK of free and liposomal SSL-DXR is a so-called "hybrid model", in which plasma disposition is described by traditional compartmental models, but plasma PK is linked to tumor drug concentrations using physiologically-based pharmacokinetic (PBPK) models that include mechanism-based terms such as tumor blood flow and tissue volume [156,157]. Model sensitivity analysis clearly identified the release rate of DXR as an important parameter for the optimization of liposomal delivery. Interestingly, after scaling the PK model from rodents to humans, preliminary simulations suggested species differences in the optimal rate of drug release. The concept of species-dependent differences in SSL-DXR PK is developed further in sections that follow.

Finer details of drug disposition have been considered in other modeling approaches. An intracellular PK model for DXR was applied to a SSL-DXR formulation [158]. Briefly, the model assumed that a mass transfer coefficient, the cell surface area, and a partition coefficient together determine DXR penetration into the cell membrane. Assumptions were that transport from the outer leaflet to the cytosol was mediated through flippases, and cytosolic DXR reversibly binds to DNA with roughly 0.18 binding sites per nucleotide. The intracellular model for DXR transport was implemented within the cellular compartment of the tumor model. Furthermore, it was possible to scale the full PK model, which included plasma, tumor, and cancer cell components, to humans by adjusting the PK parameters for free- and liposomal DXR to values derived from clinical data, as discussed below. 
Figure 2. General pharmacokinetic (PK) model diagram for liposomal drug formulations and model simulations of released drug concentration as a function of time. (A) The PK of LEP-ETU (liposomal paclitaxel) was captured using a three-compartment model, whereas a two-compartment model sufficed to describe the PK of sterically stabilized liposomes (SSL)-DXR (liposomal doxorubicin). In the model, the drug-containing liposome (L-drug) is administered into the blood ( $R_{\text {input }}$ ); it circulates within the compartment $A_{\mathrm{L} \text {-drug }}$ and can undergo clearance with drug still encapsulated $\left(\mathrm{CL}_{\mathrm{L} \text {-drug}}\right)$. The liposome releases drug according to a first-order release rate constant $\left(k_{\text {rel }}\right)$. Drug equilibrates between protein-bound $\left(A_{\mathrm{b}}\right)$ and unbound (free) $\left(A_{\mathrm{f}}\right)$ states, and distributes to peripheral tissues (compartments $A_{1}, A_{2}$ ) with inter-compartment clearances from the first peripheral compartment $\left(\mathrm{CLD}_{1}\right)$ and from the second peripheral compartment $\left(\mathrm{CLD}_{2}\right)$. For both liposomal drug formulations, the released drug is eliminated from the central compartment with a linear clearance $\mathrm{CL}_{\mathrm{drug}}$. For LEP-ETU, paclitaxel binds to plasma proteins in both a linear $\left(B_{\mathrm{p}}\right)$ and saturable $\left(B_{\text {sat }}\right)$ manner, depending upon concentration, whereas only linear binding is required to describe DXR; (B) Model simulations for a $10 \mathrm{mg} / \mathrm{kg}$ dose of SSL-DXR administered i.v. to mice, showing the change in plasma concentrations of unbound DXR as $k_{\text {rel }}$ parameter is varied over a 1000 -fold range around the value for SSL-DXR $\left(0.046 \mathrm{~h}^{-1}\right)$ obtained from the analysis of [153]; and (C) Model simulations for a $175 \mathrm{mg} / \mathrm{m}^{2}$ dose of LEP-ETU administered intravenously (i.v). to humans by infusion over a $3 \mathrm{~h}$ period, showing the change in plasma concentrations of released paclitaxel (PAC) as $k_{\text {rel }}$ is varied around the value for LEP-ETU $\left(1.26 \mathrm{~h}^{-1}\right)$ obtained from the analysis of [159].

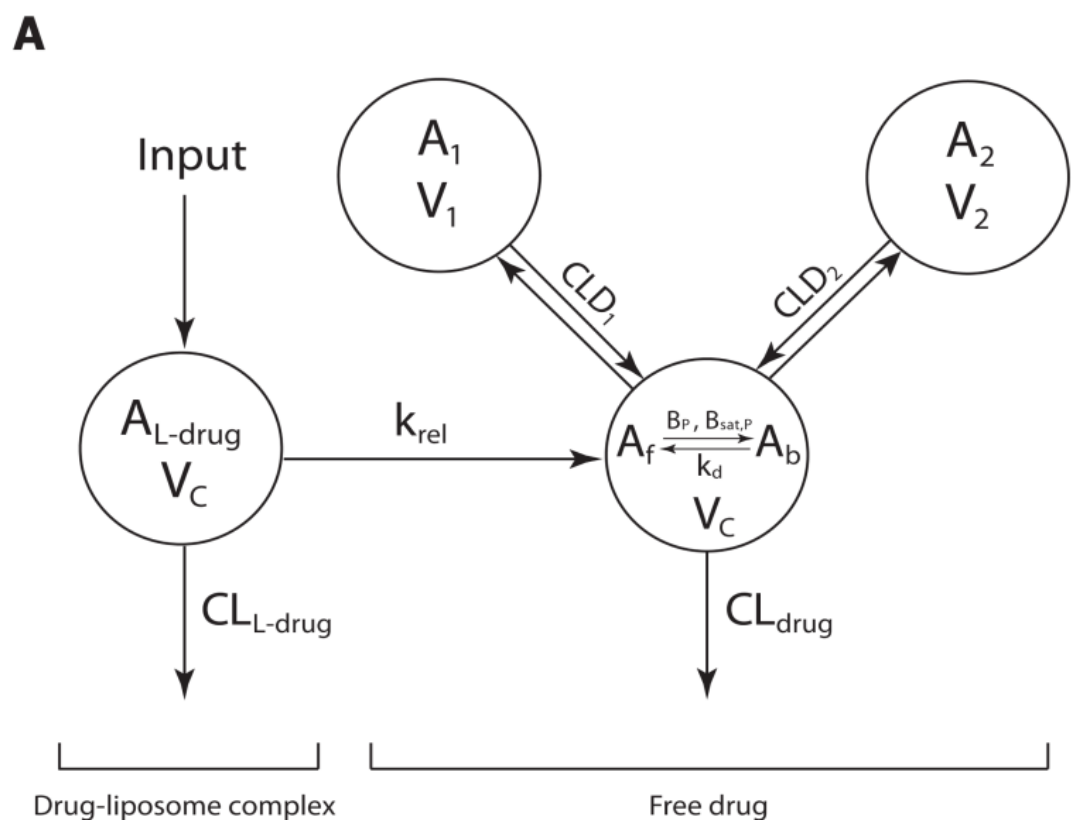


Figure 2. Cont.

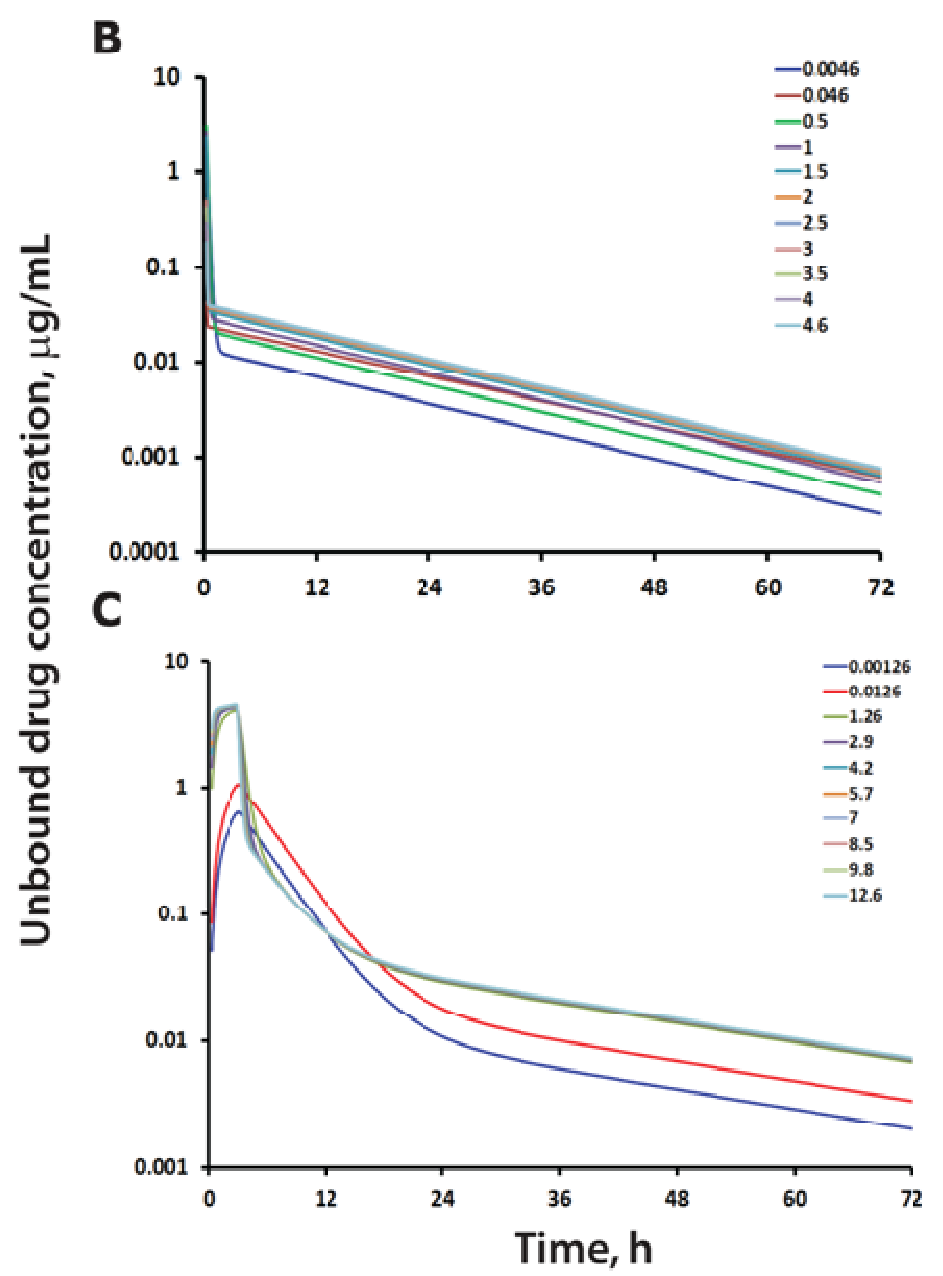

\subsection{Effect of Drug Release Rate on Plasma PK}

Drug release rates have enormous impact on biodistribution of liposome-associated drugs and on the performance of liposome-based formulations. Release rates can vary with the composition and type of liposome, the method of drug incorporation or encapsulation, and the specific properties of the drug itself. Highly hydrophobic drugs, which are generally incorporated into the liposome membrane rather than entrapped in the interior aqueous core, typically have high release rates. They can partition reversibly among plasma (or interstitial fluid), plasma proteins, and liposomes, and can be stripped by liposome interactions with hydrophobic "sinks" such as serum proteins, lipoproteins, cells in the plasma, or cells in tissues. Few robust, broadly-applicable analytical approaches have been developed to measure the release of hydrophobic, membrane-incorporated drugs from liposomes, despite the fact that drug release rates determine the biodisposition of the drug, and if sufficiently rapid, can render carrier-targeting approaches useless for controlling target deposition of drug.

To investigate the impact of drug release rates on the plasma pharmacokinetics of a liposome-associated drug, model simulations were generated for the time-course of unbound drug concentrations for two very different liposomal formulations (Figure 2): (i) LEP-ETU, a liposome-based formulation of paclitaxel (PAC), in which the drug is intercalated in the membrane bilayer; and (ii) SSL-DXR, a highly stable formulation in which doxorubicin is encapsulated in the aqueous interior 
by a "remote loading" $\mathrm{pH} /$ electrochemical gradient procedure $[67,160,161]$. Unbound drug was selected for estimation because the fraction of released drug that is not bound to plasma proteins is the pharmacologically active form. Figure 2A shows a general schematic of the two models that were utilized [153,159]. The model assumptions are that liposomal drugs (L-drug) are injected into the vascular compartment while incorporated within a liposomal carrier "compartment" ( $A_{\mathrm{L}-\mathrm{drug}}$ ), from which free drug $\left(A_{\text {drug }}\right)$ is released through a first-order process having a rate constant $\left(k_{\text {rel }}\right)$. Encapsulated drug that remains within the liposome can also be cleared with a linear clearance $\left(\mathrm{CL}_{\mathrm{L}-\text { drug }}\right)$. Carrier-released drug can exist in a free, unbound state, or can bind to plasma proteins in either a linear fashion, with a constant plasma-bound fraction $\left(B_{\mathrm{p}}\right)$ (as assumed for DXR), or with both linear- $\left(B_{\mathrm{p}}\right)$ and capacity-limited saturable bound fractions $\left(B_{\text {sat }}\right)$. An equilibrium dissociation constant $\left(K_{\mathrm{D}}\right)$ accounts for those cases in which drug equilibrates between the unbound (free) and bound states, as assumed for PAC. Free drug is cleared from the blood linearly with a clearance rate $\left(\mathrm{CL}_{\mathrm{drug}}\right)$, or distributes to one or more peripheral compartments $\left(A_{\mathrm{i}}\right)$ via a distributional clearance rate $\left(\mathrm{CL}_{\mathrm{Di}}\right)$.

In the first set of simulations, the mean estimated drug release term $k_{\text {rel }}$ for SSL-DXR was varied 1000 -fold around a baseline value for $k_{\text {rel }}$ of $0.046 \mathrm{~h}^{-1}$ (release half-life of $15 \mathrm{~h}$ ), which was determined from a previous analysis of SSL-DXR PK data in various model systems [153]. The simulations showed that increases in $k_{\text {rel }}$ up to 100 -fold above the baseline value had relatively little effect upon unbound DXR concentration or the duration of the distribution phase. In contrast, decreasing $k_{\text {rel }}$ 10-fold below the baseline value (to $0.0046 \mathrm{~h}^{-1}$ ) resulted in a decrease in unbound DXR plasma concentrations and a progressive lengthening of the distribution phase (Figure $2 \mathrm{~B}$ ). These simulations demonstrate that the distribution of unbound drug is better controlled with a slow drug release rate.

A second set of simulations examined the effect of changes in $k_{\text {rel }}$ for paclitaxel in LEP-ETU. A previous analysis of published clinical data for four paclitaxel formulations estimated $k_{\text {rel }}$ values in the range of 0.7 to $5.2 \mathrm{~h}^{-1}$; a baseline $k_{\text {rel }}$ of $1.26 \mathrm{~h}^{-1}(0.55 \mathrm{~h}$ half-life $)$ was estimated for PAC in LEP-ETU [159]. Simulations with the model (Figure 2C) show that increases in $k_{\text {rel }}$ up to 10-fold above the baseline have little effect on the PK profile of unbound PAC. In contrast, decreasing $k_{\text {rel }}$ to values 100 -fold below the baseline (from $1.26 \mathrm{~h}^{-1}$ to $0.0126 \mathrm{~h}^{-1}$ ) results in progressive decreases in unbound plasma drug concentrations, and a prolongation of the distribution phase.

A hypothesis based upon these simulations is that the mean estimates of $k_{\text {rel }}$ for SSL-DXR [153] and LEP-ETU [159] are close not only to their optima, but also to threshold values beyond which further changes in $k_{\text {rel }}$ alone are unlikely to result in an improved therapeutic outcome without concomitant changes in other formulation characteristics. Additional ramifications are discussed below.

\subsection{Effect of Drug Release Rate on Tumor PK}

The mechanisms by which liposomes release drug in tumors have not been elucidated well. Several hypotheses have been proposed, but little direct evidence has been provided, primarily because of the difficulties of monitoring drug release within tissues in vivo. Several factors may influence liposome destabilization and drug release, including the tumor microenvironment, the $\mathrm{pH}$ of the interstitial fluid surrounding tumor parenchyma (typically acidic compared to plasma $\mathrm{pH}$ ), enzymes released from apoptotic or inflammatory cells (such as lipases), and oxidizing radicals that may be released during an immune response against the tumor [21]. In vitro studies suggest that cellular transporters can extrude 
cytoplasmically-released compounds from the cell or that endocytosed drug may be regurgitated during endocytic vesicle recycling $[162,163]$. In vivo, macrophages residing within the tumor can degrade liposomes and liberate the encapsulated drug [4]. One study investigated the effect of interstitial fluid on the release of DXR from SSL-DXR in vitro by harvesting malignant pleural effusions [149]. The rate of drug leakage appeared to be faster in malignant effusions than in plasma $\left(t_{1 / 2}=1 \mathrm{vs} .100 \mathrm{~h}\right)$. That work also described a method for selective destabilization of liposomes within the tumor environment as a promising approach to control and increase the delivery of free drug at the tumor site, thereby improve efficacy.

\subsection{Effect of Drug Release Rate on Antitumor Efficacy}

Despite strong correlations between circulation half-life and antitumor activity of liposomal drugs, the relationship between in vivo drug release rate of liposomes and antitumor activity is more complex. In a comprehensive study evaluating several liposomal DXR formulations, increasing liposome stability was associated with increased total drug and released free drug in the tumor, and increased therapeutic efficacy [71,73,85,164]. Similarly, the antitumor pharmacodynamic effects of two liposomal formulations of irinotecan, having slow- and moderate release rates $\left(t_{1 / 2}\right.$ of release $=58.6 \mathrm{~h}$ $v s$. $14 \mathrm{~h}$ ), were evaluated in mice bearing human colon carcinoma xenografts. The slow release formulation, which used sucrose octasulfate (SOS) as an intra-liposomal drug-trapping agent, was more efficacious than the moderate-release formulation, which used polyphosphate to trap the drug instead. Published data also suggest a higher-stability vincristine formulation in sphingomyelin/cholesterol liposomes was more efficacious than a less stable formulation of DSPC/cholesterol liposomes [89].

Slow- and moderate-release formulations $\left(t_{1 / 2}\right.$ of release $\left.=27.2 \mathrm{~h} v s .15 \mathrm{~h}\right)$ of an anti-HER2 targeted immunoliposome of vinorelbine showed analogous behavior in HER2-overexpressing breast cancer (BT474) xenografts, with reduced efficacy for the faster-release form. For immunoliposomes, the stability of the phospholipid bilayer is more important than for other types of liposomes, because the drug must remain entrapped until targeting is achieved. Immunoliposomes having more rapid drug release rates could demonstrate antitumor activity if they are targeted to antigens that are easily accessible from the vasculature, such as may be the case for leukemias and lymphomas, or to micrometastases in which extravasation is rapid [165-167]. However, DXR-containing immunoliposome formulations bearing anti-CD19 and having varying drug release rates ( $t_{1 / 2}$ of $1.9 \mathrm{~h}$ to $315 \mathrm{~h}$ ) were compared in a B-cell lymphoma model. The antitumor activity correlated inversely with the drug release rates [168]: immunoliposomes with the most rapid DXR release rate demonstrated little efficacy, whereas the most stable formulations showed the greatest activity.

Where they have been established experimentally, correlations between in vivo liposome drug release rates and antitumor efficacy may not translate across animal species. First, liposomal drugs generally show longer plasma circulation half-lives in human than in rodents (e.g., SSL-DXR has a circulation $t_{1 / 2}$ of 56-59 $\mathrm{h}$ in humans [150,169] vs. 21-23 $\mathrm{h}$ in rodents [169]), suggesting that greater stability may be required in humans in order to maximize tumor deposition. Second, the tumor growth rate generally is slower in humans than in most animal xenograft models. Thus a therapeutically optimal release rate may be considerably faster in mice, in which efficacy may be driven by how 
rapidly drug is delivered to the tumor and establishes its pharmacological effect. Rapid tumor growth may favor more rapidly-releasing formulations, as has been concluded in analysis such as [156], which is discussed in greater detail below. In slower-growing human tumors, sustained delivery or extended exposure of the tumor to released drug may be more efficacious than rapid, short-term exposures. This situation may be analogous to preclinical experiments that consistently demonstrate improved antitumor efficacy of long-circulating, slow-release SSL-DXR in mouse tumor models compared to equivalent doses of free DXR; free DXR rapidly establishes high peak levels in tumor but clears quickly from the tumor when blood concentrations of drug decline [170]. Interestingly, a recent multi-scale analysis suggest that in humans, free DXR may be more efficacious than SSL-DXR under certain specific conditions relating to tumor perfusion and vascular permeability [110]. Overall, there are few studies that permit direct and quantitative comparison of the effect of in vivo drug-release rates for liposomal formulations upon the observed efficacy in preclinical species vs. humans. Further studies, supported by mathematical PK/PD and systems pharmacological modeling, are required to establish the conditions under which animal studies that optimize liposomal drug release rates for antitumor efficacy correlate with human clinical outcomes.

\subsection{Influence of Liposomal Drug Deposition on Antitumor Efficacy}

The influence of tumor drug deposition and the effect of liposomal lipid composition on therapeutic efficacy was evaluated for DXR using human tumor xenografts in immunodeficient mice [171]. A pegylated SSL-DXR formulation was shown to be more effective than free DXR and other non-pegylated liposomal formulations of DXR, and SSL-DXR efficacy was observed at doses lower than the maximal tolerated dose of free DXR, indicating a net therapeutic advantage for the liposomal formulation. A subsequent study compared the activity of escalating doses of SSL-DXR vs. free DXR in a xenograft mouse model of Lewis lung carcinoma. SSL-DXR at $1-2 \mathrm{mg} / \mathrm{kg}$ was equipotent in activity to free DXR at $6 \mathrm{mg} / \mathrm{kg}$, indicating a 3-6-fold increase in drug efficacy [172]. Similarly, the $50 \%$ lethal dose of SSL-DXR was nearly twice that of free DXR after a single intravenous injection in mice [68], and in rabbits, the cardiac toxicity of SSL-DXR was considerably less than that of free DXR in a multiple dose study [173].

Liposome-mediated drug delivery has limitations, given that drug transport and deposition are controlled by tumor structure and drug-specific properties $[174,175]$. Whereas drug transport via the blood stream and across the tumor vascular barrier is dominated by convection, a transport mechanism that is relatively insensitive to molecular mass, the subsequent distribution into the tumor interstitium after extravasation is dominated by diffusion, which is slower than convection and heavily influenced by molecular mass or radius of hydration [174]. With relatively few exceptions, there exists a general lack of quantitative, model-based analysis of the dynamic interplay of liposome deposition and delivery events within the tumor. Several compartmental and physiologically-based models have been used to quantify transport processes across rodent and human scales [176], and mechanism-based models have been developed that integrate drug interactions with cell-specific surface receptors and ligands [177].

One investigation developed a compartmental model to analyze and compare the performance of unencapsulated DXR, and DXR encapsulated in SSL vs. thermo-sensitive liposomes, at different 
doses, and with bolus injection vs. continuous infusions of varying duration [178]. Relationships were developed between plasma and tumor concentrations of drug, and rates of drug equilibration into tumor cells were estimated. Simulations with the model suggested that continuous infusion of DXR is superior. The antitumor efficacy of SSL-DXR was estimated to approach the efficacy of continuous-infusion DXR only if drug release rates are optimal. However, the optimal release rate estimated is more rapid than achieved by DXR liposome formulations currently used clinically. Surprisingly, the analysis suggested that the extended circulation time of sterically-stabilized liposomes conferred little therapeutic advantage over conventional liposomes. Model predictions for thermo-sensitive liposomes suggested a potential advantage at some doses, provided the hyperthermia is applied locally and drug leakage in plasma is not accelerated.

Another investigation developed a hybrid PK model for unencapsulated DXR and DXR encapsulated in liposomes of varying circulation time and drug release rates. The overall biodistributional PK was described by a simple compartmental model that estimated liposome clearance from the blood by leakage and by RES-mediated clearance. The biodistributional PK was linked to a PBPK model that represented drug concentrations in the tumor capillaries, interstitial space, and tumor cells. The model captured the time course of free DXR concentration in the extracellular space, and was linked to a pharmacodynamic model for tumor cell kill kinetics [156]. The simulations suggested that for rats, reducing the rates of RES clearance and drug release enhanced tumor drug delivery and efficacy of liposomes. However, whereas efficacy continued to increase as RES clearance was decreased, there existed an optimum for the drug release rate of approximately $0.06 \mathrm{~h}^{-1}$, which matches the release rate of DXR from long-circulating liposomes in rodents. In the model, the optimal drug release rate in rats was independent of the tumor proliferation rate, the sensitivity of tumor cells to DXR, or the tumor blood flow-rate. Interestingly, an exploratory extension of the model to humans showed that in humans, the optimal drug release rate did vary with tumor cell proliferation rate and sensitivity to DXR. For rapidly-dividing tumor cells, a release rate of $0.06 \mathrm{~h}^{-1}$ provided better efficacy, whereas for slowly-dividing tumor cells, lower release rates improved efficacy. Tumors that were relatively high in sensitivity to DXR were relatively less sensitive to drug release rate.

A subsequent mechanistic model [158] was developed to analyze tumor delivery of SSL-DXR and unencapsulated DXR that integrated multiple scales and processes, including plasma PK, tumor physiology, subcellular drug transport, and DXR distribution into the DNA of cancer cells. The kinetics of drug biodistribution were described using a one-compartment PK model for liposomes, and a two-compartment model for unencapsulated or liposome-released DXR. It was assumed that liposomal drug was released according to a first-order process. The plasma PK model was linked to a physiologically-based tumor compartment using estimates of tumor blood volumes and flow. The model assumed that for liposomal DXR to be active in tumor cells, the drug must first be released from liposomes, and that after release, it behaved identically to unencapsulated DXR. The cellular transport component of the model assumed that once DXR is released in the tumor, it partitions into the cell membrane and then is reversibly transported from the outer- to inner- leaflet of the membrane via flippases, dissociates into the cytosol, and then binds reversibly to DNA in the nucleus. This cellular model was embedded within the overall mechanism-based PK model. The analysis and modeling demonstrated that liposome PK and deposition can vary based on liposomes and tumor properties, and plays a major role in controlling overall tumor cell exposure to the drug. As discussed further below, a 
major factor in determining efficacy was the degree to which the EPR effect promoted tumor delivery of SSL-DXR.

\subsection{Interrelationships of Release Rates, Deposition, and Efficacy}

The effects of drug release and tumor deposition are presented separately above, but are highly inter-related in terms of overall efficacy, and have conceptual importance for the design of formulations and therapies of optimal performance. A decrease in $k_{\text {rel }}$ translates into a slower release of drug from the liposome, and the overall pharmacokinetics of the system will trend toward the pharmacokinetics of the liposome carrier. Conversely, progressive increases in $k_{\text {rel }}$ result in overall PK trending toward that of the free drug. But the ramifications of these changes in $k_{\text {rel }}$ are intertwined with the pharmacokinetics of the liposome carrier, and with the potency of the drug relative to the desired effect endpoint. Free, unbound drug is the mediator of pharmacological activity. Therefore, antitumor efficacy and drug toxicity may be altered considerably as unbound drug concentrations, which are driven by $k_{\text {rel }}$, change. Reducing drug release rates below some threshold value, at which the drug is cleared faster than it is released, means that unbound drug concentrations will decrease. For stable, long-circulating formulations in which tumor delivery of drug-loaded liposomes, rather than tumor exposure to released drug, controls efficacy, reducing $k_{\text {rel }}$ could lower systemic toxicity. Conversely, for cases in which longer duration of release and sustained exposure to unbound concentrations of a high-potency drug is therapeutically advantageous, reducing $k_{\text {rel }}$ could reduce efficacy. Reductions in $k_{\text {rel }}$ could have a second ramification: if release rates are lowered to values at which the clearance rate of drug from the tumor exceeds the release rate within the tumor, then tumor cell delivery (via endocytosis or other mechanisms) will become increasingly important for efficacy.

For shorter circulating liposome formulations, the ramifications of changes in $k_{\text {rel }}$ are somewhat different. Taxane formulations such as LEP-ETU provide an excellent example of the complexities. The model for LEP-ETU (Figure 2A) includes estimates for clearance of drug-loaded liposomes ( $\mathrm{CL}_{\mathrm{L}-\text { drug }}$ ). The low- $\mathrm{T}_{\mathrm{m}}$, slightly charged, somewhat large liposomes of LEP-ETU have a short

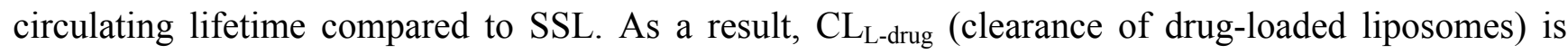
significant. Also, $k_{\text {rel }}$ is relatively high. Therefore, reductions in $k_{\text {rel }}$ below a certain threshold result in a reduction in unbound plasma PAC concentrations because drug-loaded liposomes, the source of unbound PAC, would be cleared from the blood before they release drug to the plasma. Interestingly, paclitaxel-mediated neutropenia, one biomarker of toxicity, is related to the time-over-threshold-concentration of unbound drug [179]. It appears from the modeling that the unique combination of $\mathrm{CL}_{\mathrm{L}-\text { drug }}$ (liposome PK) and $k_{\text {rel }}$ for LEP-ETU results in high initial unbound drug concentrations that fall more rapidly below the toxicity threshold than they do with Taxol ${ }^{\circledR}$, the conventional clinical formulation of PAC, and this complex interplay of $\mathrm{CL}_{\mathrm{L}-\text { drug }}$ and $k_{\text {rel }}$ could be responsible for the lower toxicity of LEP-ETU compared to Taxol ${ }^{\circledR}$ [159]. This is an important hypothesis to test experimentally.

\subsection{Analysis of Tumor Priming that Promotes Liposome Deposition}

One therapeutic strategy to enhance nanoparticulate drug deposition and distribution within solid tumors is "tumor priming". The concept is that treatment with an initial agent will compromise the 
tumor:blood delivery barrier so as to permit greater tumor deposition and intra-tumor distribution of a subsequently-administered agent, in this case, nanoparticle drug carriers. Intrinsic to this strategy is that a temporal "window of opportunity" is created that governs the success of delivery of the second agent, and that identifying the optimal inter-dose interval is essential. There are numerous examples of priming strategies that employ chemotherapy drugs, enzymes that degrade tumor interstitial components, inhibitors of specific signaling pathways that reduce tumor stromal density, and others. One recent strategy for which a linked pharmacokinetic and pharmacodynamic analysis was developed employed an initial treatment with paclitaxel, which creates a wave of apoptosis within solid tumors, resulting in altered tumor vascular perfusion/permeability, reduced tumor interstitial pressure and cellular density, and increased intra-tumor diffusion [180,181]. The subsequently-delivered agent was SSL-DXR [181]. It was observed experimentally that a $48 \mathrm{~h}$ inter-dose interval increased SSL-DXR tumor deposition, efficacy, and time to tumor regrowth. The reverse, "non-priming" sequence did not show the equivalent efficacy.

In order to develop a hypothesis describing the linkage between PK and PD in tumor priming strategies, a quantitative system pharmacological model was developed using available data from the literature [155,181-185]. The final model [153] captured the observed data [181] for the PK of paclitaxel and SSL-DXR as single agents, as well as effects on tumor drug exposure, cellular responses such as apoptosis, and tumor volume progression when the drugs were administered alone, combined in a priming-inducing sequence, or administered in the reverse, non-priming sequence. One simplification of the model was that for both drugs, apoptosis was assumed to be the sole cause of death, and therefore the time course of apoptosis, which exhibits a considerable lag period, drove pharmacodynamic interactions. An important characteristic of the final model was that in order to capture the PK and PD effects of PAC tumor priming, it was necessary to hypothesize a feedback loop through which the tumor apoptotic response elicited by PAC drove an increase in tumor permeability to SSL-DXR, which resulted in enhanced deposition. For the reverse, non-priming sequence, no feedback loop was required to link initial SSL-DXR deposition to subsequent paclitaxel deposition or effect.

The PK and PD predictions of the model were highly sensitive to the inter-dose interval, which, in turn, determine the interrelationship between the temporal lag of the apoptotic cascade, progressing from initiation to cell death over a period of $24-48 \mathrm{~h}$, and the changes in tumor permeability that increased deposition and efficacy of the subsequent SSL-DXR dose. Simulations with the final model (Figure 3) suggested that a shorter inter-dose interval than tested experimentally could be optimal for DXR deposition and would increase efficacy drastically, with 2.5-fold greater SSL-DXR deposition in the tumor achieved by halving the $48 \mathrm{~h}$ inter-dose interval to $24 \mathrm{~h}$. The model also predicted that efficacy (time to tumor progression) would mirror drug deposition, and would be greatest with a $24 \mathrm{~h}$ inter-dose interval. Experimental testing of the model predictions will be valuable. No experimental data existed for other important tumor responses to priming, such as the degree of tumor interstitial pressure reduction and its time course. Reduction in the outward convective fluid force could have major impact on SSL-DXR deposition in tumor priming sequences. This and additional phenomena that are perturbed in tumor priming strategies could be integrated in a future predictive model, and tested experimentally. 
Figure 3. Effect of inter-dose interval between PAC administered for tumor priming upon tumor exposure and efficacy of a subsequently-administered dose of SSL-DXR. Each symbol represents the area under the effect curve $\left(\mathrm{AUC}_{0 \text {-inf }}\right)$ of $\mathrm{DXR}$ released from liposomes (red squares, left ordinate) and the time to-tumor progression (defined as the time for tumor volume to double; blue circles, right ordinate) achieved as the inter-dose interval is varied according to the time indicated by the abscissa. Results are extracted from the analysis of [153].
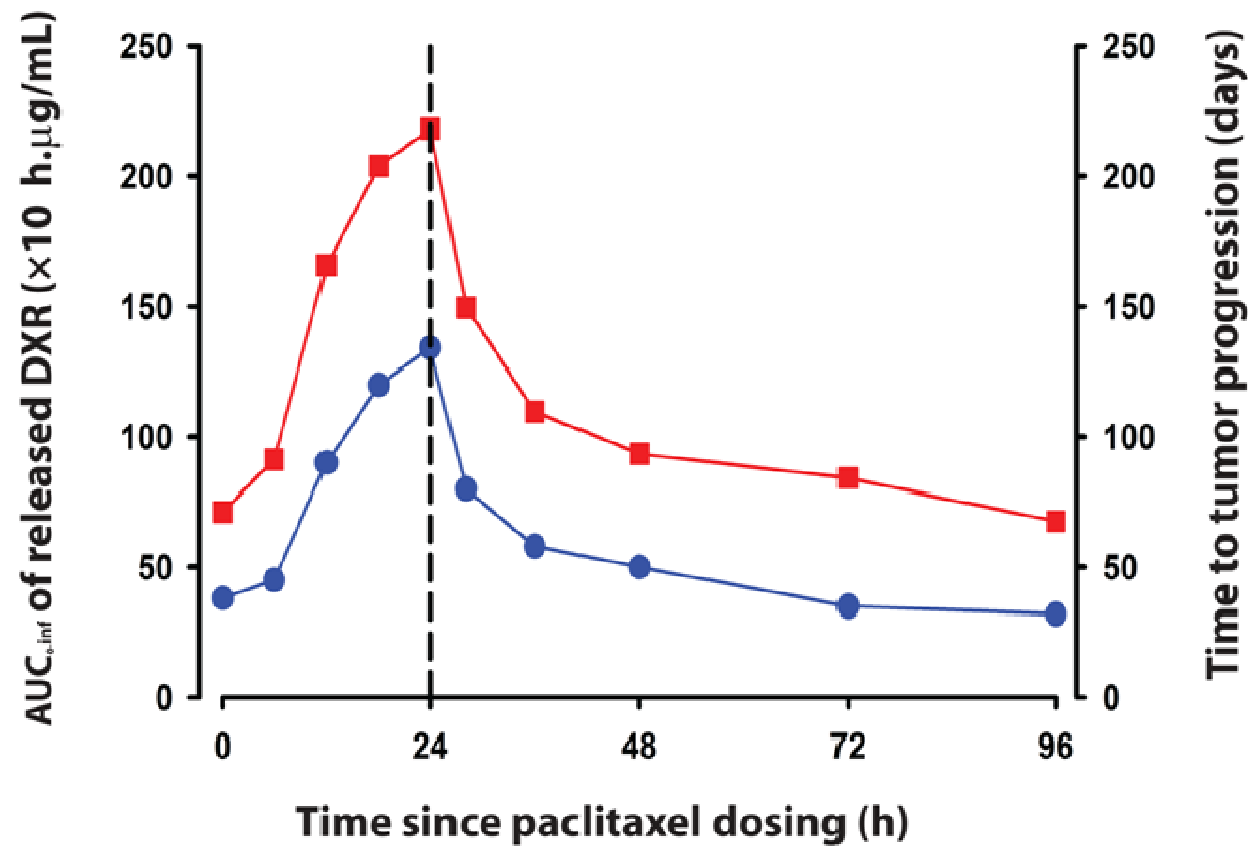

\section{Translation of PK System Parameters from Animal Models to Humans}

Multi-scale predictive modeling of parameters controlling liposome formulation performance is not well developed but would be very valuable for bridging preclinical and clinical development of oncology drugs. In some cases, relatively simple approaches can be applied to existing data to obtain species-bridging- or species-independent parameters. One example is a study that investigated a liposomal formulation of the hydrophobic anti-fungal drug amphotericin B. Drug release kinetics were estimated using compartmental modeling that compared the PK of liposomal- and unencapsulated drug formulations. A key assumption was that the micellar deoxycholate drug carrier used for the unencapsulated drug was diluted rapidly to a concentration at which it would no longer influence the PK of the unencapsulated drug, and therefore the PK of the unencapsulated drug represents the PK of drug released from the liposome. A single, species-independent first-order release rate constant $\left(t_{1 / 2}\right.$ of release $=198 \mathrm{~h}$ ) was estimated for rats and humans [91]. Drug release kinetics were then incorporated into vascular- and tissue sub-compartments of PBPK models to describe amphotericin B biodistribution in mice and rats, systems for which such data were available, and then to predict the pharmacokinetics of the drug in human tissues.

Alternatively, mechanism-based PK models offer the advantage of identifying drug- and system-specific factors that determine the magnitude and time-course of pharmacological processes. They offer a unique opportunity to integrate simultaneously information obtained from in vitro 
analytical assays and in vivo animal studies, and provide a potential means to anticipate both therapeutic and adverse responses to drugs in humans. A multi-scale PK model was developed recently for free DXR and SSL-DXR [158] in mice and humans that is based on mechanistic hypotheses underlying drug delivery for both formulations on organismal, tissue, and cellular levels. The model developed made it feasible to scale and compare PK system parameters obtained from in vitro data, preclinical models, and humans, so as to make predictions as to what factors would favor un-encapsulated DXR vs. SSL-DXR in humans. Table 2 summarizes the key PK system parameters from [158] that could be scaled to bridge formulation PK between mice and humans. The analysis estimated that SSL-DXR plasma half-lives were approxiamtely 3-fold greater in humans than in mice, whereas the clearance of unencapsulated DXR in humans was approxiamtely 4-fold lower than in mice. Free DXR transport coefficients in mice were estimated based upon human data: clinical studies that employed dynamic contrast-enhanced magnetic resonance (DCE-MR) imaging with gadolinium-based contrast agents allowed the fitting of a coefficient for DXR transport into human tumors (transvascular flux into the tumor for DXR; tvf_in_dox) based upon an underlying assumption that gadolinium has similar diffusive transport characteristics as free DXR [186-188]. The coefficient parameter for DXR transport out of the tumor (tvf_out_dox) was also fitted from human data for SSL-DXR and unencapsulated DXR [29]. For DXR, the tumor influx parameter tvf_in_dox was approxiamtely 12-fold greater in humans than mice, and the efflux (tvf_out_dox) was approxiamtely 7-fold greater in humans. For SSL-DXR, the inward transvascular flux coefficient for liposomes (tvf_in_lipo) was estimated from available clinical data [47,189], and the outward transvascular flux (from the tumor interstitial space to the capillary space, tvf_out_lipo) was based upon data from mouse models [115]. After normalization of the data per unit surface area, both inward and outward flux of liposomes was assumed to be equivalent for humans and mice.

Table 2. Systems parameters that can be scaled up from animals to humans for liposomal doxorubicin (DXR). Adapted with permission from [158]. Copyright 2014 Nature.

\begin{tabular}{|c|c|c|c|}
\hline Parameter (unit) & Definition & $\begin{array}{l}\text { Value } \\
\left(\frac{\text { human }}{\text { mouse }} \text { ratio }\right) \dagger\end{array}$ & References \\
\hline \multicolumn{4}{|l|}{ Mouse DXR } \\
\hline k12_DXR (1/min) & $\begin{array}{l}\text { Rate constant of DXR transport from central to } \\
\text { peripheral compartment }\end{array}$ & $\begin{array}{l}0.74 \\
(0.1)\end{array}$ & {$[158]$} \\
\hline k21_DXR (1/min) & $\begin{array}{l}\text { Rate constant of DXR transport from peripheral to } \\
\text { central compartment }\end{array}$ & $\begin{array}{l}5.5 \times 10^{-3} \\
(0.2)\end{array}$ & {$[158]$} \\
\hline kel_DXR (1/min) & $\begin{array}{l}\text { Rate constant of DXR elimination from central } \\
\text { compartment }\end{array}$ & $\begin{array}{l}0.36 \\
(0.2)\end{array}$ & {$[158]$} \\
\hline $\begin{array}{l}\text { tvf_in_DXR } \\
(\mathrm{cm} / \mathrm{min})\end{array}$ & $\begin{array}{l}\text { Transvascular flux per surface area for DXR from } \\
\text { capillary to interstitial space }\end{array}$ & $\begin{array}{l}2.96 \times 10^{-4} \\
(12.3)\end{array}$ & {$[158]$} \\
\hline $\begin{array}{l}\text { tvf_out_DXR } \\
(\mathrm{cm} / \mathrm{min})\end{array}$ & $\begin{array}{l}\text { Transvascular flux per surface area for DXR from } \\
\text { interstitial to capillary space }\end{array}$ & $\begin{array}{l}1.18 \times 10-3 \\
(7.2)\end{array}$ & {$[158]$} \\
\hline
\end{tabular}


Table 2. Cont.

\begin{tabular}{|c|c|c|c|}
\hline Parameter (unit) & Definition & $\begin{array}{l}\text { Value } \\
\left(\frac{\text { human }}{\text { mouse }} \text { ratio }\right) \dagger\end{array}$ & References \\
\hline \multicolumn{4}{|l|}{ Mouse Liposome } \\
\hline kel_lipo (1/min) & $\begin{array}{l}\text { Rate constant of liposome elimination from central } \\
\text { compartment }\end{array}$ & $\begin{array}{l}1.14 \times 10^{-3} \\
(0.1)\end{array}$ & {$[158]$} \\
\hline $\begin{array}{l}\text { tvf_in_lipo } \\
(\mathrm{cm} / \mathrm{min})\end{array}$ & $\begin{array}{l}\text { Transvascular flux per surface area for liposome } \\
\text { from capillary to interstitial space }\end{array}$ & $\begin{array}{l}2.64 \times 10^{-6} \\
(1.0)\end{array}$ & {$[158]$} \\
\hline $\begin{array}{l}\text { tvf_out_lipo } \\
(\mathrm{cm} / \mathrm{min})\end{array}$ & $\begin{array}{l}\text { Transvascular flux per surface area for liposome } \\
\text { from interstitial to capillary space }\end{array}$ & $\begin{array}{l}7.14 \times 10^{-6} \\
(1.0)\end{array}$ & {$[158]$} \\
\hline \multicolumn{4}{|l|}{ Human DXR } \\
\hline k12_DXR (1/min) & $\begin{array}{l}\text { Rate constant of DXR transport from central to } \\
\text { peripheral compartment }\end{array}$ & $\begin{array}{l}4.75 \times 10^{-2} \\
(0.1)\end{array}$ & {$[158]$} \\
\hline k21_DXR (1/min) & $\begin{array}{l}\text { Rate constant of DXR transport from peripheral to } \\
\text { central compartment }\end{array}$ & $\begin{array}{l}1.25 \times 10^{-3} \\
(0.2)\end{array}$ & {$[158]$} \\
\hline kel_DXR (1/min) & $\begin{array}{l}\text { Rate constant of DXR elimination from central } \\
\text { compartment }\end{array}$ & $\begin{array}{l}8.2 \times 10^{-2} \\
(0.2)\end{array}$ & {$[158]$} \\
\hline $\begin{array}{l}\text { tvf_in_DXR } \\
(\mathrm{cm} / \mathrm{min})\end{array}$ & $\begin{array}{l}\text { Rate constant of DXR elimination from central } \\
\text { compartment }\end{array}$ & $\begin{array}{l}3.63 \times 10^{-3} \\
(12.3)\end{array}$ & [186-188] \\
\hline $\begin{array}{l}\text { tvf_out_DXR } \\
(\mathrm{cm} / \mathrm{min})\end{array}$ & $\begin{array}{l}\text { Rate constant of liposome elimination from central } \\
\text { compartment }\end{array}$ & $\begin{array}{l}8.45 \times 10^{-3} \\
(7.2)\end{array}$ & {$[158]$} \\
\hline \multicolumn{4}{|l|}{ Human Liposome } \\
\hline kel_lipo (1/min) & $\begin{array}{l}\text { Rate constant of liposome elimination from central } \\
\text { compartment }\end{array}$ & $\begin{array}{l}1.67 \times 10^{-4} \\
(0.1)\end{array}$ & {$[47]$} \\
\hline $\begin{array}{l}\text { tvf_in_lipo } \\
(\mathrm{cm} / \mathrm{min})\end{array}$ & $\begin{array}{l}\text { Transvascular flux per surface area for liposome } \\
\text { from capillary to interstitial space }\end{array}$ & $\begin{array}{l}2.64 \times 10^{-6} \\
(1.0)\end{array}$ & {$[158]$} \\
\hline $\begin{array}{l}\text { tvf_out_lipo } \\
(\mathrm{cm} / \mathrm{min})\end{array}$ & $\begin{array}{l}\text { Transvascular flux per surface area for liposome } \\
\text { from interstitial to capillary space }\end{array}$ & $\begin{array}{l}7.14 \times 10^{-6} \\
(1.0)\end{array}$ & {$[158]$} \\
\hline \multicolumn{4}{|l|}{ Tumor } \\
\hline Qtumor (L/min $/ \mathrm{kg})$ & Blood flow into tumor & $\begin{array}{l}2.82 \times 10^{-2} \\
(0.1)\end{array}$ & {$[176,190]$} \\
\hline
\end{tabular}

${ }^{\dagger}$ Fold difference between human and mouse parameter estimates.

By comparing the estimates of liposome deposition parameters for various types of tumors, it was concluded from the system analysis that in some solid tumors such as breast cancers, liposome permeability was lower than in other tumors such as Kaposi's sarcoma. The overall conclusion from the modeling and analysis was that with certain combinations of characteristics, such as low tumor vascular permeability to liposomes, unencapsulated DXR might be more efficacious than SSL-DXR. The model made clear predictions as to which factors determine superior or inferior therapeutic performance of a liposomal formulation $v s$. unencapsulated drug, and identified parameters that would be important in extending this type of analysis to other liposomal formulations. A data- and mechanism-based analysis for comparing other nanoparticulate formulations with unencapsulated 
drugs could both speed clinical development and enable stratification of patients so as to treat each with the most efficacious DXR dosage form.

\section{Conclusions}

Significant advances have been made over the past several decades in understanding the physicochemical factors that affect the pharmacokinetics of oncology drugs in liposome-based formulations. Yet development of a quantitative formalism for describing drug- and carrier pharmacokinetic behavior lags in comparison to available literature on other comparatively new therapeutic entities, such as immunoglobulins or antibody-drug conjugates. As a result, the selection of complimentary drug- and carrier properties for liposomal formulations, and the development of therapeutic combinations that integrate nanoparticulates such as liposomes, remains largely empirical. Nonetheless, there exists a growing number of examples of the successful progression of oncology drugs formulated in lipidic nanocarriers to advanced clinical development or approval. Often, the extended plasma half-life and sustained release characteristics of liposomal formulations improves the overall therapeutic index, usually because of a reduction in toxicity, but occasionally improvements in antitumor efficacy are observed. It is expected that more examples of increased antitumor efficacy may be obtained as clinical scientists learn how to optimize multi-drug therapies that exploit the unique properties of nanoparticulate drug carriers in combination with conventional or novel therapeutic agents. Further enhancements in antitumor activity and target cell selectivity may be achieved in the future as ligand-targeted lipidic nanocarriers make their way through preclinical and clinical testing.

Advances continue to be made in liposomal formulation development and optimization of their performance in specific clinical applications. With a growing understanding of the physicochemical and pharmacological factors that dictate pharmacokinetics and pharmacodynamics of liposome-incorporated oncology drugs, it is possible to envisage quantitative PK/PD modeling and simulation as a fundamental tool for (i) designing formulations having the desired pharmacological properties for specific applications; (ii) quantifying primary pharmacological and physiological processes controlling their disposition, biodistribution, and rate of delivery at the site of action; (iii) providing insights into the determinants of efficacy and safety that are operant in vivo; and (iv) assisting translational research that bridges data from preclinical animal models to anticipate performance in clinical settings. A recent example of how computational systems analysis can provide insights into the species scalability of oncology drug delivery from preclinical mouse models to human clinical performance [158] was able to derive and compare the hypothesized key parameters that govern liposomal drug delivery to target cells and overall efficacy at both mouse and human scales. This approach represents a significant advance. However, these and other systems analyses will be advanced further if the essential data underlying key determinants of liposome performance are obtained systematically during preclinical and clinical development.

Whereas regulatory guidance for industry on liposomal drug formulations provides recommendations on the chemistry, manufacturing controls, human PK and bioavailability, and labeling documentation for liposome drug products submitted in new drug applications (NDA) [191], there has been relatively little emphasis upon the use of computational tools that could streamline the development of novel liposomal formulations or provide a better means to improve the PK and PD 
characteristics of existing formulations. Mathematical models are economical and flexible by reason of their scalable parameters. They can be adapted continually and modified or extended to new circumstances as our understanding of the biology of the system and the pharmacology of the carrier formulation increases in detail. Indeed, with the aid of computational model simulations of drug delivery to tumors, and the downstream pharmacodynamics that result, it is possible to imagine that drug/carrier formulations might be designed and optimized for clinical use based on computational models capturing key performance parameters, much as the design and refinement of drugs depends heavily upon computational approaches.

\section{Acknowledgments}

Partial support was derived from grants from the University at Buffalo Center for Protein Therapeutics consortium (D.E.M.) and National Institutes of Health grant CA168454 (R.M.S.).

\section{Author Contributions}

Dr. Sihem Ait-Oudhia performed the model simulations and wrote the review. Dr. Donald E. Mager and Dr. Robert M. Straubinger supervised and contributed to the editing of the review.

\section{Conflicts of Interest}

The authors declare no conflict of interest.

\section{References}

1. Torchilin, V.P. Recent advances with liposomes as pharmaceutical carriers. Nat. Rev. Drug Discov. 2005, 4, 145-160.

2. Slingerland, M.; Guchelaar, H.J.; Gelderblom, H. Liposomal drug formulations in cancer therapy: 15 years along the road. Drug Discov. Today 2012, 17, 160-166.

3. Drummond, D.C.; Meyer, O.; Hong, K.; Kirpotin, D.B.; Papahadjopoulos, D. Optimizing liposomes for delivery of chemotherapeutic agents to solid tumors. Pharmacol. Rev. 1999, 51, 691-743.

4. Storm, G.; ten Kate, M.T.; Working, P.K.; Bakker-Woudenberg, I.A. Doxorubicin entrapped in sterically stabilized liposomes: Effects on bacterial blood clearance capacity of the mononuclear phagocyte system. Clin. Cancer Res. 1998, 4, 111-115.

5. Gregoriadis, G. Overview of liposomes. J. Antimicrob. Chemother. 1991, 28, 39-48.

6. Drummond, D.C.; Noble, C.O.; Hayes, M.E.; Park, J.W.; Kirpotin, D.B. Pharmacokinetics and in vivo drug release rates in liposomal nanocarrier development. J. Pharm. Sci. 2008, 97, 4696-4740.

7. Oude Blenke, E.; Mastrobattista, E.; Schiffelers, R.M. Strategies for triggered drug release from tumor targeted liposomes. Expert Opin. Drug Deliv. 2013, 10, 1399-1410.

8. Li, L.; ten Hagen, T.L.; Bolkestein, M.; Gasselhuber, A.; Yatvin, J.; van Rhoon, G.C.; Eggermont, A.M.; Haemmerich, D.; Koning, G.A. Improved intratumoral nanoparticle extravasation and penetration by mild hyperthermia. J. Control. Release 2013, 167, 130-137. 
9. Li, L.; ten Hagen, T.L.; Hossann, M.; Suss, R.; van Rhoon, G.C.; Eggermont, A.M.; Haemmerich, D.; Koning, G.A. Mild hyperthermia triggered doxorubicin release from optimized stealth thermosensitive liposomes improves intratumoral drug delivery and efficacy. J. Control. Release 2013, 168, 142-150.

10. Chang, H.I.; Yeh, M.K. Clinical development of liposome-based drugs: Formulation, characterization, and therapeutic efficacy. Int. J. Nanomedicine 2012, 7, 49-60.

11. Guo, W.; Johnson, J.L.; Khan, S.; Ahmad, A.; Ahmad, I. Paclitaxel quantification in mouse plasma and tissues containing liposome-entrapped paclitaxel by liquid chromatography-tandem mass spectrometry: Application to a pharmacokinetics study. Anal. Biochem. 2005, 336, 213-220.

12. Sharma, A.; Mayhew, E.; Bolcsak, L.; Cavanaugh, C.; Harmon, P.; Janoff, A.; Bernacki, R.J. Activity of paclitaxel liposome formulations against human ovarian tumor xenografts. Int. J. Cancer 1997, 71, 103-107.

13. Sharma, A.; Mayhew, E.; Straubinger, R.M. Antitumor effect of taxol-containing liposomes in a taxol-resistant murine tumor model. Cancer Res. 1993, 53, 5877-5881.

14. Lim, H.J.; Masin, D.; Madden, T.D.; Bally, M.B. Influence of drug release characteristics on the therapeutic activity of liposomal mitoxantrone. J. Pharmacol. Exp Ther. 1997, 281, 566-573.

15. Forssen, E.A.; Male-Brune, R.; Adler-Moore, J.P.; Lee, M.J.; Schmidt, P.G.; Krasieva, T.B.; Shimizu, S.; Tromberg, B.J. Fluorescence imaging studies for the disposition of daunorubicin liposomes (DaunoXome) within tumor tissue. Cancer Res. 1996, 56, 2066-2075.

16. Kim, E.S.; Lu, C.; Khuri, F.R.; Tonda, M.; Glisson, B.S.; Liu, D.; Jung, M.; Hong, W.K.; Herbst, R.S. A phase II study of STEALTH cisplatin (SPI-77) in patients with advanced non-small cell lung cancer. Lung Cancer 2001, 34, 427-432.

17. Lu, C.; Perez-Soler, R.; Piperdi, B.; Walsh, G.L.; Swisher, S.G.; Smythe, W.R.; Shin, H.J.; Ro, J.Y.; Feng, L.; Truong, M.; et al. Phase II study of a liposome-entrapped cisplatin analog (L-NDDP) administered intrapleurally and pathologic response rates in patients with malignant pleural mesothelioma. J. Clin. Oncol. 2005, 23, 3495-3501.

18. Tardi, P.; Choice, E.; Masin, D.; Redelmeier, T.; Bally, M.; Madden, T.D. Liposomal encapsulation of topotecan enhances anticancer efficacy in murine and human xenograft models. Cancer Res. 2000, 60, 3389-3393.

19. Pal, A.; Khan, S.; Wang, Y.F.; Kamath, N.; Sarkar, A.K.; Ahmad, A.; Sheikh, S.; Ali, S.; Carbonaro, D.; Zhang, A.; et al. Preclinical safety, pharmacokinetics and antitumor efficacy profile of liposome-entrapped SN-38 formulation. Anticancer Res. 2005, 25, 331-341.

20. Emerson, D.L.; Bendele, R.; Brown, E.; Chiang, S.; Desjardins, J.P.; Dihel, L.C.; Gill, S.C.; Hamilton, M.; LeRay, J.D.; Moon-McDermott, L.; et al. Antitumor efficacy, pharmacokinetics, and biodistribution of NX 211: A low-clearance liposomal formulation of lurtotecan. Clin. Cancer Res. 2000, 6, 2903-2912.

21. Drummond, D.C.; Noble, C.O.; Guo, Z.; Hong, K.; Park, J.W.; Kirpotin, D.B. Development of a highly active nanoliposomal irinotecan using a novel intraliposomal stabilization strategy. Cancer Res. 2006, 66, 3271-3277.

22. Krishna, R.; Webb, M.S.; St Onge, G.; Mayer, L.D. Liposomal and nonliposomal drug pharmacokinetics after administration of liposome-encapsulated vincristine and their contribution to drug tissue distribution properties. J. Pharmacol. Exp. Ther. 2001, 298, 1206-1212. 
23. Zhigaltsev, I.V.; Maurer, N.; Akhong, Q.F.; Leone, R.; Leng, E.; Wang, J.; Semple, S.C.; Cullis, P.R. Liposome-encapsulated vincristine, vinblastine and vinorelbine: A comparative study of drug loading and retention. J. Control. Release 2005, 104, 103-111.

24. Cosco, D.; Paolino, D.; Muzzalupo, R.; Celia, C.; Citraro, R.; Caponio, D.; Picci, N.; Fresta, M. Novel PEG-coated niosomes based on bola-surfactant as drug carriers for 5-fluorouracil. Biomed. Microdevices 2009, 11, 1115-1125.

25. Storm, G.; Crommelin, D.J.A. Liposomes: Quo vadis? Pharm. Sci. Technol. Today 1998, 1, 19-31.

26. Matsumura, Y.; Maeda, H. A new concept for macromolecular therapeutics in cancer chemotherapy: Mechanism of tumoritropic accumulation of proteins and the antitumor agent smancs. Cancer Res. 1986, 46, 6387-6392.

27. Celia, C.; Cosco, D.; Paolino, D.; Fresta, M. Gemcitabine-loaded innovative nanocarriers vs. GEMZAR: Biodistribution, pharmacokinetic features and in vivo antitumor activity. Expert Opin. Drug Deliv. 2011, 8, 1609-1629.

28. Stewart, S.; Jablonowski, H.; Goebel, F.D.; Arasteh, K.; Spittle, M.; Rios, A.; Aboulafia, D.; Galleshaw, J.; Dezube, B.J. Randomized comparative trial of pegylated liposomal doxorubicin versus bleomycin and vincristine in the treatment of AIDS-related Kaposi's sarcoma. J. Clin. Oncol. 1998, 16, 683-691.

29. Northfelt, D.W.; Dezube, B.J.; Thommes, J.A.; Miller, B.J.; Fischl, M.A.; Friedman-Kien, A.; Kaplan, L.D.; Du Mond, C.; Mamelok, R.D.; Henry, D.H. Pegylated-liposomal doxorubicin versus doxorubicin, bleomycin, and vincristine in the treatment of AIDS-related Kaposi's sarcoma: results of a randomized phase III clinical trial. J. Clin. Oncol. 1998, 16, 2445-2451.

30. Cianfrocca, M.; Lee, S.; von Roenn, J.; Tulpule, A.; Dezube, B.J.; Aboulafia, D.M.; Ambinder, R.F.; Lee, J.Y.; Krown, S.E.; Sparano, J.A. Randomized trial of paclitaxel versus pegylated liposomal doxorubicin for advanced human immunodeficiency virus-associated Kaposi sarcoma: Evidence of symptom palliation from chemotherapy. Cancer 2010, 116, 3969-3977.

31. Gordon, A.N.; Fleagle, J.T.; Guthrie, D.; Parkin, D.E.; Gore, M.E.; Lacave, A.J. Recurrent epithelial ovarian carcinoma: A randomized phase III study of pegylated liposomal doxorubicin versus topotecan. J. Clin. Oncol. 2001, 19, 3312-3322.

32. Pignata, S.; Scambia, G.; Savarese, A.; Breda, E.; Sorio, R.; Pisano, C.; Lorusso, D.; Cognetti, F.; Vernaglia Lombardi, A.; Gebbia, V.; et al. Carboplatin and pegylated liposomal doxorubicin for advanced ovarian cancer: Preliminary activity results of the MITO-2 phase III trial. Oncology 2009, 76, 49-54.

33. Markman, M.; Moon, J.; Wilczynski, S.; Lopez, A.M.; Rowland, K.M., Jr.; Michelin, D.P.; Lanzotti, V.J.; Anderson, G.L.; Alberts, D.S. Single agent carboplatin versus carboplatin plus pegylated liposomal doxorubicin in recurrent ovarian cancer: Final survival results of a SWOG (S0200) phase 3 randomized trial. Gynecol. Oncol. 2010, 116, 323-325.

34. Pujade-Lauraine, E.; Wagner, U.; Aavall-Lundqvist, E.; Gebski, V.; Heywood, M.; Vasey, P.A.; Volgger, B.; Vergote, I.; Pignata, S.; Ferrero, A.; et al. Pegylated liposomal Doxorubicin and Carboplatin compared with Paclitaxel and Carboplatin for patients with platinum-sensitive ovarian cancer in late relapse. J. Clin. Oncol. 2010, 28, 3323-3329. 
35. Keller, A.M.; Mennel, R.G.; Georgoulias, V.A.; Nabholtz, J.M.; Erazo, A.; Lluch, A.; Vogel, C.L.; Kaufmann, M.; von Minckwitz, G.; Henderson, I.C.; et al. Randomized phase III trial of pegylated liposomal doxorubicin versus vinorelbine or mitomycin $\mathrm{C}$ plus vinblastine in women with taxane-refractory advanced breast cancer. J. Clin. Oncol. 2004, 22, 3893-3901.

36. Chan, S.; Davidson, N.; Juozaityte, E.; Erdkamp, F.; Pluzanska, A.; Azarnia, N.; Lee, L.W. Phase III trial of liposomal doxorubicin and cyclophosphamide compared with epirubicin and cyclophosphamide as first-line therapy for metastatic breast cancer. Ann. Oncol. 2004, 15, 1527-1534.

37. Sparano, J.A.; Makhson, A.N.; Semiglazov, V.F.; Tjulandin, S.A.; Balashova, O.I.; Bondarenko, I.N.; Bogdanova, N.V.; Manikhas, G.M.; Oliynychenko, G.P.; Chatikhine, V.A.; et al. Pegylated liposomal doxorubicin plus docetaxel significantly improves time to progression without additive cardiotoxicity compared with docetaxel monotherapy in patients with advanced breast cancer previously treated with neoadjuvant-adjuvant anthracycline therapy: Results from a randomized phase III study. J. Clin. Oncol. 2009, 27, 4522-4529.

38. Alba, E.; Ruiz-Borrego, M.; Margeli, M.; Rodriguez-Lescure, A.; Sanchez-Rovira, P.; Ruiz, A.; Mel-Lorenzo, J.R.; Ramos-Vazquez, M.; Ribelles, N.; Calvo, E.; et al. Maintenance treatment with pegylated liposomal doxorubicin versus observation following induction chemotherapy for metastatic breast cancer: GEICAM 2001-01 study. Breast Cancer Res. Treat. 2010, 122, 169-176.

39. Rifkin, R.M.; Gregory, S.A.; Mohrbacher, A.; Hussein, M.A. Pegylated liposomal doxorubicin, vincristine, and dexamethasone provide significant reduction in toxicity compared with doxorubicin, vincristine, and dexamethasone in patients with newly diagnosed multiple myeloma: A Phase III multicenter randomized trial. Cancer 2006, 106, 848-858.

40. Orlowski, R.Z.; Nagler, A.; Sonneveld, P.; Blade, J.; Hajek, R.; Spencer, A.; San Miguel, J.; Robak, T.; Dmoszynska, A.; Horvath, N.; et al. Randomized phase III study of pegylated liposomal doxorubicin plus bortezomib compared with bortezomib alone in relapsed or refractory multiple myeloma: Combination therapy improves time to progression. J. Clin. Oncol. 2007, 25, 3892-3901.

41. Sonneveld, P.; Hajek, R.; Nagler, A.; Spencer, A.; Blade, J.; Robak, T.; Zhuang, S.H.; Harousseau, J.L.; Orlowski, R.Z. Combined pegylated liposomal doxorubicin and bortezomib is highly effective in patients with recurrent or refractory multiple myeloma who received prior thalidomide/lenalidomide therapy. Cancer 2008, 112, 1529-1537.

42. Gill, P.S.; Wernz, J.; Scadden, D.T.; Cohen, P.; Mukwaya, G.M.; von Roenn, J.H.; Jacobs, M.; Kempin, S.; Silverberg, I.; Gonzales, G.; et al. Randomized phase III trial of liposomal daunorubicin versus doxorubicin, bleomycin, and vincristine in AIDS-related Kaposi's sarcoma. J. Clin. Oncol. 1996, 14, 2353-2364.

43. Latagliata, R.; Breccia, M.; Fazi, P.; Iacobelli, S.; Martinelli, G.; di Raimondo, F.; Sborgia, M.; Fabbiano, F.; Pirrotta, M.T.; Zaccaria, A.; et al. Liposomal daunorubicin versus standard daunorubicin: Long term follow-up of the GIMEMA GSI 103 AMLE randomized trial in patients older than 60 years with acute myelogenous leukaemia. Br. J. Haematol. 2008, 143, 681-689.

44. Glantz, M.J.; LaFollette, S.; Jaeckle, K.A.; Shapiro, W.; Swinnen, L.; Rozental, J.R.; Phuphanich, S.; Rogers, L.R.; Gutheil, J.C.; Batchelor, T.; et al. Randomized trial of a slow-release versus a standard formulation of cytarabine for the intrathecal treatment of lymphomatous meningitis. J. Clin. Oncol. 1999, 17, 3110-3116. 
45. Booser, D.J.; Esteva, F.J.; Rivera, E.; Valero, V.; Esparza-Guerra, L.; Priebe, W.; Hortobagyi, G.N. Phase II study of liposomal annamycin in the treatment of doxorubicin-resistant breast cancer. Cancer Chemother. Pharmacol. 2002, 50, 6-8.

46. Wetzler, M.; Thomas, D.A.; Wang, E.S.; Shepard, R.; Ford, L.A.; Heffner, T.L.; Parekh, S.; Andreeff, M.; O’Brien, S.; Kantarjian, H.M. Phase I/II trial of nanomolecular liposomal annamycin in adult patients with relapsed/refractory acute lymphoblastic leukemia. Clin. Lymphoma Myeloma Leuk. 2013, 13, 430-434.

47. Harrington, K.J.; Lewanski, C.R.; Northcote, A.D.; Whittaker, J.; Wellbank, H.; Vile, R.G.; Peters, A.M.; Stewart, J.S. Phase I-II study of pegylated liposomal cisplatin (SPI-077) in patients with inoperable head and neck cancer. Ann. Oncol. 2001, 12, 493-496.

48. Seetharamu, N.; Kim, E.; Hochster, H.; Martin, F.; Muggia, F. Phase II study of liposomal cisplatin (SPI-77) in platinum-sensitive recurrences of ovarian cancer. Anticancer Res. 2010, 30, 541-545.

49. White, S.C.; Lorigan, P.; Margison, G.P.; Margison, J.M.; Martin, F.; Thatcher, N.; Anderson, H.; Ranson, M. Phase II study of SPI-77 (sterically stabilised liposomal cisplatin) in advanced non-small-cell lung cancer. Br. J. Cancer 2006, 95, 822-828.

50. Stathopoulos, G.P.; Antoniou, D.; Dimitroulis, J.; Stathopoulos, J.; Marosis, K.; Michalopoulou, P. Comparison of liposomal cisplatin versus cisplatin in non-squamous cell non-small-cell lung cancer. Cancer Chemother. Pharmacol. 2011, 68, 945-950.

51. De Jonge, M.J.; Slingerland, M.; Loos, W.J.; Wiemer, E.A.; Burger, H.; Mathijssen, R.H.; Kroep, J.R.; den Hollander, M.A.; van der Biessen, D.; Lam, M.H.; et al. Early cessation of the clinical development of LiPlaCis, a liposomal cisplatin formulation. Eur. J. Cancer 2010, 46, 3016-3021.

52. Dragovich, T.; Mendelson, D.; Kurtin, S.; Richardson, K.; von Hoff, D.; Hoos, A. A Phase II trial of the liposomal DACH platinum L-NDDP in patients with therapy-refractory advanced colorectal cancer. Cancer Chemother. Pharmacol. 2006, 58, 759-764.

53. Celsion coporation. Available online: http://celsion.com/docs/technology_thermodox (accessed on 10 March 2014).

54. Katsumata, N.; Fujiwara, Y.; Kamura, T.; Nakanishi, T.; Hatae, M.; Aoki, D.; Tanaka, K.; Tsuda, H.; Kamiura, S.; Takehara, K.; et al. Phase II clinical trial of pegylated liposomal doxorubicin (JNS002) in Japanese patients with mullerian carcinoma (epithelial ovarian carcinoma, primary carcinoma of fallopian tube, peritoneal carcinoma) having a therapeutic history of platinum-based chemotherapy: A Phase II study of the Japanese Gynecologic Oncology Group. Jpn. J. Clin. Oncol. 2008, 38, 777-785.

55. Duffaud, F.; Borner, M.; Chollet, P.; Vermorken, J.B.; Bloch, J.; Degardin, M.; Rolland, F.; Dittrich, C.; Baron, B.; Lacombe, D.; et al. Phase II study of OSI-211 (liposomal lurtotecan) in patients with metastatic or loco-regional recurrent squamous cell carcinoma of the head and neck. An EORTC new drug development group study. Eur. J. Cancer 2004, 40, 2748-2752.

56. Gokhale, P.C.; Pei, J.; Zhang, C.; Ahmad, I.; Rahman, A.; Kasid, U. Improved safety, pharmacokinetics and therapeutic efficacy profiles of a novel liposomal formulation of mitoxantrone. Anticancer Res. 2001, 21, 3313-3321. 
57. Infante, J.R.; Keedy, V.L.; Jones, S.F.; Zamboni, W.C.; Chan, E.; Bendell, J.C.; Lee, W.; Wu, H.; Ikeda, S.; Kodaira, H.; et al. Phase I and pharmacokinetic study of IHL-305 (PEGylated liposomal irinotecan) in patients with advanced solid tumors. Cancer Chemother. Pharmacol. 2012, 70, 699-705.

58. Roy, A.C.; Park, S.R.; Cunningham, D.; Kang, Y.K.; Chao, Y.; Chen, L.T.; Rees, C.; Lim, H.Y.; Tabernero, J.; Ramos, F.J.; et al. A randomized phase II study of PEP02 (MM-398), irinotecan or docetaxel as a second-line therapy in patients with locally advanced or metastatic gastric or gastro-oesophageal junction adenocarcinoma. Ann. Oncol. 2013, 24, 1567-1573.

59. Senzer, N.M.; Matsuno, K.; Yamagata, N.; Fujisawa, T.; Wasserman, E.; Sutherland, W.; Sharma, S.; Phan, A. MBP-426, a novel liposome-encapsulated oxaliplatin, in combination with 5-FU/leucovorin (LV): Phase I results of a Phase I/II study in gastro-esophageal adenocarcinoma, with pharmacokinetics. Mol. Cancer Ther. 2009, 8, 12-19.

60. Rodriguez, M.A.; Pytlik, R.; Kozak, T.; Chhanabhai, M.; Gascoyne, R.; Lu, B.; Deitcher, S.R.; Winter, J.N. Vincristine sulfate liposomes injection (Marqibo) in heavily pretreated patients with refractory aggressive non-Hodgkin lymphoma: Report of the pivotal phase II study. Cancer 2009, 115, 3475-3482.

61. Batist, G.; Gelmon, K.A.; Chi, K.N.; Miller, W.H., Jr.; Chia, S.K.; Mayer, L.D.; Swenson, C.E.; Janoff, A.S.; Louie, A.C. Safety, pharmacokinetics, and efficacy of CPX-1 liposome injection in patients with advanced solid tumors. Clin. Cancer Res. 2009, 15, 692-700.

62. Feldman, E.J.; Lancet, J.E.; Kolitz, J.E.; Ritchie, E.K.; Roboz, G.J.; List, A.F.; Allen, S.L.; Asatiani, E.; Mayer, L.D.; Swenson, C.; et al. First-in-man study of CPX-351: A liposomal carrier containing cytarabine and daunorubicin in a fixed 5:1 molar ratio for the treatment of relapsed and refractory acute myeloid leukemia. J. Clin. Oncol. 2011, 29, 979-985.

63. Young, R.C.; Ozols, R.F.; Myers, C.E. The anthracycline antineoplastic drugs. N. Engl. J. Med. 1981, 305, 139-153.

64. Nichols, J.W.; Deamer, D.W. Catecholamine uptake and concentration by liposomes maintaining pH gradients. Biochim. Biophys. Acta 1976, 455, 269-271.

65. Mayer, L.D.; Bally, M.B.; Hope, M.J.; Cullis, P.R. Uptake of antineoplastic agents into large unilamellar vesicles in response to a membrane potential. Biochim. Biophys. Acta 1985, 816, 294-302.

66. Madden, T.D.; Harrigan, P.R.; Tai, L.C.; Bally, M.B.; Mayer, L.D.; Redelmeier, T.E.; Loughrey, H.C.; Tilcock, C.P.; Reinish, L.W.; Cullis, P.R. The accumulation of drugs within large unilamellar vesicles exhibiting a proton gradient: A survey. Chem. Phys. Lipids 1990, 53, 37-46.

67. Lasic, D.D.; Frederik, P.M.; Stuart, M.C.; Barenholz, Y.; McIntosh, T.J. Gelation of liposome interior. A novel method for drug encapsulation. FEBS Lett. 1992, 312, 255-258.

68. Haran, G.; Cohen, R.; Bar, L.K.; Barenholz, Y. Transmembrane ammonium sulfate gradients in liposomes produce efficient and stable entrapment of amphipathic weak bases. Biochim. Biophys. Acta 1993, 1151, 201-215.

69. Cullis, P.R.; Hope, M.J.; Bally, M.B.; Madden, T.D.; Mayer, L.D.; Fenske, D.B. Influence of pH gradients on the transbilayer transport of drugs, lipids, peptides and metal ions into large unilamellar vesicles. Biochim. Biophys. Acta 1997, 1331, 187-211. 
70. Zucker, D.; Marcus, D.; Barenholz, Y.; Goldblum, A. Liposome drugs' loading efficiency: A working model based on loading conditions and drug's physicochemical properties. J. Control. Release 2009, 139, 73-80.

71. Charrois, G.J.; Allen, T.M. Drug release rate influences the pharmacokinetics, biodistribution, therapeutic activity, and toxicity of pegylated liposomal doxorubicin formulations in murine breast cancer. Biochim. Biophys. Acta 2004, 1663, 167-177.

72. Johnston, M.J.; Edwards, K.; Karlsson, G.; Cullis, P.R. Influence of drug-to-lipid ratio on drug release properties and liposome integrity in liposomal doxorubicin formulations. J. Liposome Res. 2008, 18, 145-157.

73. Laginha, K.M.; Verwoert, S.; Charrois, G.J.; Allen, T.M. Determination of doxorubicin levels in whole tumor and tumor nuclei in murine breast cancer tumors. Clin. Cancer Res. 2005, 11, 6944-6949.

74. Lim, H.J.; Masin, D.; McIntosh, N.L.; Madden, T.D.; Bally, M.B. Role of drug release and liposome-mediated drug delivery in governing the therapeutic activity of liposomal mitoxantrone used to treat human A431 and LS180 solid tumors. J. Pharmacol. Exp. Ther. 2000, 292, 337-345.

75. Ishida, T.; Harashima, H.; Kiwada, H. Liposome clearance. Biosci. Rep. 2002, 22, 197-224.

76. Moghimi, S.M.; Hunter, A.C.; Andresen, T.L. Factors controlling nanoparticle pharmacokinetics: An integrated analysis and perspective. Annu. Rev. Pharmacol. Toxicol. 2012, 52, 481-503.

77. Senior, J.H. Fate and behavior of liposomes in vivo: A review of controlling factors. Crit. Rev. Ther. Drug Carrier Syst. 1987, 3, 123-193.

78. Weinstein, J.N. Liposomes as drug carriers in cancer therapy. Cancer Treat. Rep. 1984, 68, 127-135.

79. Gregoriadis, G. The carrier potential of liposomes in biology and medicine (second of two parts). N. Engl. J. Med. 1976, 295, 765-770.

80. Gregoriadis, G. The carrier potential of liposomes in biology and medicine (first of two parts). N. Engl. J. Med. 1976, 295, 704-710.

81. Patel, H.M. Influence of lipid composition on opsonophagocytosis of liposomes. Res. Immunol. 1992, 143, 242-244.

82. Devine, D.V.; Marjan, J.M. The role of immunoproteins in the survival of liposomes in the circulation. Crit. Rev. Ther. Drug Carrier Syst. 1997, 14, 105-131.

83. Ohlson, M.; Sorensson, J.; Haraldsson, B. Glomerular size and charge selectivity in the rat as revealed by FITC-ficoll and albumin. Am. J. Physiol. Renal Physiol. 2000, 279, F84-F91.

84. Lund, U.; Rippe, A.; Venturoli, D.; Tenstad, O.; Grubb, A.; Rippe, B. Glomerular filtration rate dependence of sieving of albumin and some neutral proteins in rat kidneys. Am. J. Physiol. Renal Physiol. 2003, 284, F1226-F1234.

85. Allen, T.M.; Cheng, W.W.; Hare, J.I.; Laginha, K.M. Pharmacokinetics and pharmacodynamics of lipidic nano-particles in cancer. Anticancer Agents Med. Chem. 2006, 6, 513-523.

86. Adlakha-Hutcheon, G.; Bally, M.B.; Shew, C.R.; Madden, T.D. Controlled destabilization of a liposomal drug delivery system enhances mitoxantrone antitumor activity. Nat. Biotechnol. 1999, $17,775-779$.

87. Hitzman, C.J.; Wiedmann, T.S.; Dai, H.; Elmquist, W.F. Measurement of drug release from microcarriers by microdialysis. J. Pharm. Sci. 2005, 94, 1456-1466. 
88. Musteata, F.M.; Pawliszyn, J.; Qian, M.G.; Wu, J.T.; Miwa, G.T. Determination of drug plasma protein binding by solid phase microextraction. J. Pharm. Sci. 2006, 95, 1712-1722.

89. Webb, M.S.; Harasym, T.O.; Masin, D.; Bally, M.B.; Mayer, L.D. Sphingomyelin-cholesterol liposomes significantly enhance the pharmacokinetic and therapeutic properties of vincristine in murine and human tumour models. Br. J. Cancer 1995, 72, 896-904.

90. Bulitta, J.B.; Zhao, P.; Arnold, R.D.; Kessler, D.R.; Daifuku, R.; Pratt, J.; Luciano, G.; Hanauske, A.R.; Gelderblom, H.; Awada, A.; et al. Mechanistic population pharmacokinetics of total and unbound paclitaxel for a new nanodroplet formulation versus Taxol in cancer patients. Cancer Chemother. Pharmacol. 2009, 63, 1049-1063.

91. Kagan, L.; Gershkovich, P.; Wasan, K.M.; Mager, D.E. Physiologically based pharmacokinetic model of amphotericin $\mathrm{B}$ disposition in rats following administration of deoxycholate formulation (Fungizone(R)): Pooled analysis of published data. AAPS J. 2011, 13, 255-264.

92. Jain, R.K. Transport of molecules in the tumor interstitium: A review. Cancer Res. 1987, 47, 3039-3051.

93. Jain, R.K. Delivery of novel therapeutic agents in tumors: Physiological barriers and strategies. J. Natl. Cancer Inst. 1989, 81, 570-576.

94. Jain, R.K. Vascular and interstitial barriers to delivery of therapeutic agents in tumors. Cancer Metastasis Rev. 1990, 9, 253-266.

95. Jain, R.K. Physiological barriers to delivery of monoclonal antibodies and other macromolecules in tumors. Cancer Res. 1990, 50, 814-819.

96. Papahadjopoulos, D.; Allen, T.M.; Gabizon, A.; Mayhew, E.; Matthay, K.; Huang, S.K.; Lee, K.D.; Woodle, M.C.; Lasic, D.D.; Redemann, C.; et al. Sterically stabilized liposomes: Improvements in pharmacokinetics and antitumor therapeutic efficacy. Proc. Natl. Acad. Sci. USA 1991, 88, 11460-11464.

97. Yuan, F.; Leunig, M.; Huang, S.K.; Berk, D.A.; Papahadjopoulos, D.; Jain, R.K. Microvascular permeability and interstitial penetration of sterically stabilized (STEALTH) liposomes in a human tumor xenograft. Cancer Res. 1994, 54, 3352-3356.

98. Jain, R.K. Delivery of molecular medicine to solid tumors. Science 1996, 271, 1079-1080.

99. Yuan, F.; Salehi, H.A.; Boucher, Y.; Vasthare, U.S.; Tuma, R.F.; Jain, R.K. Vascular permeability and microcirculation of gliomas and mammary carcinomas transplanted in rat and mouse cranial windows. Cancer Res. 1994, 54, 4564-4568.

100. Seymour, L.W. Passive tumor targeting of soluble macromolecules and drug conjugates. Crit. Rev. Ther. Drug Carrier Syst. 1992, 9, 135-187.

101. Huang, S.K.; Martin, F.J.; Jay, G.; Vogel, J.; Papahadjopoulos, D.; Friend, D.S. Extravasation and transcytosis of liposomes in Kaposi's sarcoma-like dermal lesions of transgenic mice bearing the HIV tat gene. Am. J. Pathol. 1993, 143, 10-14.

102. Sarti, P.; Ginobbi, P.; D’Agostino, I.; Arancia, G.; Lendaro, E.; Molinari, A.; Ippoliti, R.; Citro, G. Liposomal targeting of leukaemia HL60 cells induced by transferrin-receptor endocytosis. Biotechnol. Appl. Biochem. 1996, 24, 269-276.

103. Park, J.W.; Hong, K.; Carter, P.; Asgari, H.; Guo, L.Y.; Keller, G.A.; Wirth, C.; Shalaby, R.; Kotts, C.; Wood, W.I.; et al. Development of anti-p185HER2 immunoliposomes for cancer therapy. Proc. Natl. Acad. Sci. USA 1995, 92, 1327-1331. 
104. Straubinger, R.M.; Hong, K.; Friend, D.S.; Papahadjopoulos, D. Endocytosis of liposomes and intracellular fate of encapsulated molecules: Encounter with a low $\mathrm{pH}$ compartment after internalization in coated vesicles. Cell 1983, 32, 1069-1079.

105. Heath, T.; Lopez, N.; Stern, W.; Papahadjopoulos, D. 5-Fluoroorotate: A new liposome-dependent cytotoxic agent. FEBS Lett. 1985, 187, 73-75.

106. Heath, T.D.; Brown, C.S. Liposome dependent delivery of $N$-phosphonacetyl-L-aspartic acid to cells in vitro. J. Liposome Res. 1989, 1, 303-317.

107. Matthay, K.K.; Abai, A.M.; Cobb, S.; Hong, K.; Papahadjopoulos, D.; Straubinger, R.M. Role of ligand in antibody-directed endocytosis of liposomes by human T-leukemia cells. Cancer Res. 1989, 49, 4879-4886.

108. Kirpotin, D.B.; Drummond, D.C.; Shao, Y.; Shalaby, M.R.; Hong, K.; Nielsen, U.B.; Marks, J.D.; Benz, C.C.; Park, J.W. Antibody targeting of long-circulating lipidic nanoparticles does not increase tumor localization but does increase internalization in animal models. Cancer Res. 2006, 66, 6732-6740.

109. Drummond, D.C.; Noble, C.O.; Guo, Z.; Hayes, M.E.; Connolly-Ingram, C.; Gabriel, B.S.; Hann, B.; Liu, B.; Park, J.W.; Hong, K.; et al. Development of a highly stable and targetable nanoliposomal formulation of topotecan. J. Control. Release 2010, 141, 13-21.

110. Hendriks, B.S.; Klinz, S.G.; Reynolds, J.G.; Espelin, C.W.; Gaddy, D.F.; Wickham, T.J. Impact of tumor HER2/ERBB2 expression level on HER2-targeted liposomal doxorubicin-mediated drug delivery: Multiple low-affinity interactions lead to a threshold effect. Mol. Cancer Ther. 2013, 12, 1816-1828.

111. Connor, J.; Huang, L. Efficient cytoplasmic delivery of a fluorescent dye by $\mathrm{pH}$-sensitive immunoliposomes. J. Cell Biol. 1985, 101, 582-589.

112. Straubinger, R.M.; Düzgünes, N.; Papahadjopoulos, D. pH-Sensitive liposomes mediate cytoplasmic delivery of encapsulated macromolecules. FEBS Lett. 1985, 179, 148-154.

113. Chu, C.-J.; Dijkstra, J.; Lai, M.-Z.; Hong, K.; Szoka, F.C., Jr. Efficiency of cytoplasmic delivery by $\mathrm{pH}$-sensitive liposomes to cells in culture. Pharm. Res. 1990, 7, 824-834.

114. Heath, T.; Montgomery, J.; Piper, J.; Papahadjopoulos, D. Antibody-targeted liposomes: Increase in specific toxicity of methotrexate-g-aspartate. Proc. Natl. Acad. Sci. USA. 1983, 80, 1377-1381.

115. Charrois, G.J.; Allen, T.M. Rate of biodistribution of STEALTH liposomes to tumor and skin: Influence of liposome diameter and implications for toxicity and therapeutic activity. Biochim. Biophys. Acta 2003, 1609, 102-108.

116. Nagayasu, A.; Uchiyama, K.; Kiwada, H. The size of liposomes: A factor which affects their targeting efficiency to tumors and therapeutic activity of liposomal antitumor drugs. Adv. Drug Deliv. Rev. 1999, 40, 75-87.

117. Hobbs, S.K.; Monsky, W.L.; Yuan, F.; Roberts, W.G.; Griffith, L.; Torchilin, V.P.; Jain, R.K. Regulation of transport pathways in tumor vessels: Role of tumor type and microenvironment. Proc. Natl. Acad. Sci. USA 1998, 95, 4607-4612.

118. Allen, T.M.; Hansen, C.; Rutledge, J. Liposomes with prolonged circulation times: Factors affecting uptake by reticuloendothelial and other tissues. Biochim. Biophys. Acta 1989, 981, 27-35. 
119. Woodle, M.C.; Matthay, K.K.; Newman, M.S.; Hidayat, J.E.; Collins, L.R.; Redemann, C.; Martin, F.J.; Papahadjopoulos, D. Versatility in lipid compositions showing prolonged circulation with sterically stabilized liposomes. Biochim. Biophys. Acta 1992, 1105, 193-200.

120. Gabizon, A.; Papahadjopoulos, D. Liposome formulations with prolonged circulation time in blood and enhanced uptake by tumors. Proc. Natl. Acad. Sci. USA 1988, 85, 6949-6953.

121. Allen, T.M.; Chonn, A. Large unilamellar liposomes with low uptake into the reticuloendothelial system. FEBS Lett. 1987, 223, 42-46.

122. Eastman, S.J.; Wilschut, J.; Cullis, P.R.; Hope, M.J. Intervesicular exchange of lipids with weak acid and weak base characteristics: Influence of transmembrane $\mathrm{pH}$ gradients. Biochim. Biophys. Acta 1989, 981, 178-184.

123. Mayhew, E.; Ito, M.; Lazo, R. Toxicity of non-drug-containing liposomes for cultured human cells. Exp. Cell Res. 1987, 171, 195-202.

124. Senior, J.H.; Trimble, K.R.; Maskiewicz, R. Interaction of positively-charged liposomes with blood: Implications for their application in vivo. Biochim. Biophys. Acta 1991, 1070, 173-179.

125. Gabizon, A.; Papahadjopoulos, D. The role of surface charge and hydrophilic groups on liposome clearance in vivo. Biochim. Biophys. Acta 1992, 1103, 94-100.

126. Litzinger, D.C.; Brown, J.M.; Wala, I.; Kaufman, S.A.; Van, G.Y.; Farrell, C.L.; Collins, D. Fate of cationic liposomes and their complex with oligonucleotide in vivo. Biochim. Biophys. Acta 1996, 1281, 139-149.

127. Thurston, G.; McLean, J.W.; Rizen, M.; Baluk, P.; Haskell, A.; Murphy, T.J.; Hanahan, D.; McDonald, D.M. Cationic liposomes target angiogenic endothelial cells in tumors and chronic inflammation in mice. J. Clin. Investig. 1998, 101, 1401-1413.

128. Campbell, R.B.; Fukumura, D.; Brown, E.B.; Mazzola, L.M.; Izumi, Y.; Jain, R.K.; Torchilin, V.P.; Munn, L.L. Cationic charge determines the distribution of liposomes between the vascular and extravascular compartments of tumors. Cancer Res. 2002, 62, 6831-6836.

129. Senior, J.; Gregoriadis, G. Stability of small unilamellar liposomes in serum and clearance from the circulation: The effect of the phospholipid and cholesterol components. Life Sci. 1982, 30, 2123-2136.

130. Gregoriadis, G.; Davis, C. Stability of liposomes in vivo and in vitro is promoted by their cholesterol content and the presence of blood cells. Biochem. Biophys. Res. Commun. 1979, 89, 1287-1293.

131. Allen, T.M.; Hansen, C.; Martin, F.; Redemann, C.; Yau-Young, A. Liposomes containing synthetic lipid derivatives of poly (ethylene glycol) show prolonged circulation half-lives in vivo. Biochim. Biophys. Acta 1991, 1066, 29-36.

132. Daemen, T.; Hofstede, G.; Ten Kate, M.T.; Bakker-Woudenberg, I.A.; Scherphof, G.L. Liposomal doxorubicin-induced toxicity: Depletion and impairment of phagocytic activity of liver macrophages. Int. J. Cancer 1995, 61, 716-721.

133. Woodle, M.C.; Lasic, D.D. Sterically stabilized liposomes. Biochim. Biophys. Acta 1992, 1113, 171-199.

134. Hong, K.; Kirpotin, D.B.; Park, J.W.; Shao, Y.; Shalaby, R.; Colbern, G.; Benz, C.C.; Papahadjopoulos, D. Anti-HER2 immunoliposomes for targeted drug delivery. Ann. N. Y. Acad. Sci. 1999, 886, 293-296. 
135. Sapra, P.; Allen, T.M. Internalizing antibodies are necessary for improved therapeutic efficacy of antibody-targeted liposomal drugs. Cancer Res. 2002, 62, 7190-7194.

136. Sugano, M.; Egilmez, N.K.; Yokota, S.J.; Chen, F.A.; Harding, J.; Huang, S.K.; Bankert, R.B. Antibody targeting of doxorubicin-loaded liposomes suppresses the growth and metastatic spread of established human lung tumor xenografts in severe combined immunodeficient mice. Cancer Res. 2000, 60, 6942-6949.

137. Nielsen, U.B.; Kirpotin, D.B.; Pickering, E.M.; Hong, K.; Park, J.W.; Refaat Shalaby, M.; Shao, Y.; Benz, C.C.; Marks, J.D. Therapeutic efficacy of anti-ErbB2 immunoliposomes targeted by a phage antibody selected for cellular endocytosis. Biochim. Biophys. Acta 2002, 1591, 109-118.

138. Lopes de Menezes, D.E.; Pilarski, L.M.; Allen, T.M. In vitro and in vivo targeting of immunoliposomal doxorubicin to human B-cell lymphoma. Cancer Res. 1998, 58, 3320-3330.

139. Park, J.W.; Hong, K.; Kirpotin, D.B.; Colbern, G.; Shalaby, R.; Baselga, J.; Shao, Y.; Nielsen, U.B.; Marks, J.D.; Moore, D.; et al. Anti-HER2 immunoliposomes: Enhanced efficacy attributable to targeted delivery. Clin. Cancer Res. 2002, 8, 1172-1181.

140. Mamot, C.; Drummond, D.C.; Noble, C.O.; Kallab, V.; Guo, Z.; Hong, K.; Kirpotin, D.B.; Park, J.W. Epidermal growth factor receptor-targeted immunoliposomes significantly enhance the efficacy of multiple anticancer drugs in vivo. Cancer Res. 2005, 65, 11631-11638.

141. Heath, T.D.; Fraley, R.T.; Bentz, J.; Voss, E.W., Jr.; Herron, J.N.; Papahadjopoulos, D. Antibody-directed liposomes. Determination of affinity constants for soluble and liposome-bound antifluorescein. Biochim. Biophys. Acta 1984, 770, 148-158.

142. Allen, T.M.; Newman, M.S.; Woodle, M.C.; Mayhew, E.; Uster, P.S. Pharmacokinetics and anti-tumor activity of vincristine encapsulated in sterically stabilized liposomes. Int. J. Cancer 1995, 62, 199-204.

143. Moghimi, S.M.; Szebeni, J. Stealth liposomes and long circulating nanoparticles: Critical issues in pharmacokinetics, opsonization and protein-binding properties. Prog. Lipid Res. 2003, 42, $463-478$.

144. Zhou, R.; Mazurchuk, R.; Straubinger, R.M. Antivasculature effects of doxorubicin-containing liposomes in an intracranial rat brain tumor model. Cancer Res. 2002, 62, 2561-2566.

145. Laverman, P.; Brouwers, A.H.; Dams, E.T.; Oyen, W.J.; Storm, G.; van Rooijen, N.; Corstens, F.H.; Boerman, O.C. Preclinical and clinical evidence for disappearance of long-circulating characteristics of polyethylene glycol liposomes at low lipid dose. J. Pharmacol. Exp. Ther. 2000, 293, 996-1001.

146. Ishida, T.; Ichihara, M.; Wang, X.; Yamamoto, K.; Kimura, J.; Majima, E.; Kiwada, H. Injection of PEGylated liposomes in rats elicits PEG-specific IgM, which is responsible for rapid elimination of a second dose of PEGylated liposomes. J. Control. Release 2006, 112, 15-25.

147. Ishida, T.; Atobe, K.; Wang, X.; Kiwada, H. Accelerated blood clearance of PEGylated liposomes upon repeated injections: Effect of doxorubicin-encapsulation and high-dose first injection. J. Control. Release 2006, 115, 251-258.

148. Ishida, T.; Maeda, R.; Ichihara, M.; Irimura, K.; Kiwada, H. Accelerated clearance of PEGylated liposomes in rats after repeated injections. J. Control. Release 2003, 88, 35-42.

149. Gabizon, A.; Shiota, R.; Papahadjopoulos, D. Pharmacokinetics and tissue distribution of doxorubicin encapsulated in stable liposomes with long circulation times. J. Natl. Cancer Inst. 1989, 81, 1484-1488. 
150. Lyass, O.; Uziely, B.; Ben-Yosef, R.; Tzemach, D.; Heshing, N.I.; Lotem, M.; Brufman, G.; Gabizon, A. Correlation of toxicity with pharmacokinetics of pegylated liposomal doxorubicin (Doxil) in metastatic breast carcinoma. Cancer 2000, 89, 1037-1047.

151. Lorusso, D.; di Stefano, A.; Carone, V.; Fagotti, A.; Pisconti, S.; Scambia, G. Pegylated liposomal doxorubicin-related palmar-plantar erythrodysesthesia ("hand-foot" syndrome). Ann. Oncol. 2007, 18, 1159-1164.

152. Arnold, R.D.; Mager, D.E.; Slack, J.E.; Straubinger, R.M. Effect of repetitive administration of Doxorubicin-containing liposomes on plasma pharmacokinetics and drug biodistribution in a rat brain tumor model. Clin. Cancer Res. 2005, 11, 8856-8865.

153. Ait-Oudhia, S.; Straubinger, R.M.; Mager, D.E. Systems pharmacological analysis of paclitaxel-mediated tumor priming that enhances nanocarrier deposition and efficacy. J. Pharmacol. Exp. Ther. 2013, 344, 103-112.

154. Jang, S.H.; Wientjes, M.G.; Au, J.L. Enhancement of paclitaxel delivery to solid tumors by apoptosis-inducing pretreatment: Effect of treatment schedule. J. Pharmacol. Exp. Ther. 2001, 296, 1035-1042.

155. Xiong, X.B.; Huang, Y.; Lu, W.L.; Zhang, H.; Zhang, X.; Zhang, Q. Enhanced intracellular uptake of sterically stabilized liposomal Doxorubicin in vitro resulting in improved antitumor activity in vivo. Pharm. Res. 2005, 22, 933-939.

156. Harashima, H.; Tsuchihashi, M.; Iida, S.; Doi, H.; Kiwada, H. Pharmacokinetic/pharmacodynamic modeling of antitumor agents encapsulated into liposomes. Adv. Drug Deliv. Rev. 1999, 40, 39-61.

157. Harashima, H.; Iida, S.; Urakami, Y.; Tsuchihashi, M.; Kiwada, H. Optimization of antitumor effect of liposomally encapsulated doxorubicin based on simulations by pharmacokinetic/pharmacodynamic modeling. J. Control. Release 1999, 61, 93-106.

158. Hendriks, B.S.; Reynolds, J.G.; Klinz, S.G.; Geretti, E.; Lee, H.; Leonard, S.C.; Gaddy, D.F.; Espelin, C.W.; Nielsen, U.B.; Wickham, T.J. Multiscale kinetic modeling of liposomal doxorubicin delivery quantifies the role of tumor and drug-specific parameters in local delivery to tumors. Clin. Pharmacol. Ther. 2012, 1, 1-11.

159. Ait-Oudhia, S.; Straubinger, R.M.; Mager, D.E. Meta-analysis of nanoparticulate paclitaxel delivery system pharmacokinetics and model prediction of associated neutropenia. Pharm. Res. 2012, 29, 2833-2844.

160. Mayer, L.D.; Bally, M.B.; Cullis, P.R. Uptake of adriamycin into large unilamellar vesicles in response to a pH gradient. Biochim. Biophys. Acta 1986, 857, 123-126.

161. Harrigan, P.R.; Wong, K.F.; Redelmeier, T.E.; Wheeler, J.J.; Cullis, P.R. Accumulation of doxorubicin and other lipophilic amines into large unilamellar vesicles in response to transmembrane pH-gradients. Biochim. Biophys. Acta 1993, 1149, 329-348.

162. Oh, Y.-K.; Straubinger, R.M. Cellular retention of liposome-delivered compounds modulated by a probenecid-sensitive anion transporter. Pharm. Res. 1997, 14, 1203-1209.

163. Straubinger, R.M.; Lopez, N.G.; Debs, R.; Hong, K.; Papahadjopoulos, D. Liposome-based therapy of human ovarian cancer: Parameters determining potency of negatively-charged and antibody-targeted liposomes. Cancer Res. 1988, 48, 5237-5245. 
164. Paolino, D.; Cosco, D.; Racanicchi, L.; Trapasso, E.; Celia, C.; Iannone, M.; Puxeddu, E.; Costante, G.; Filetti, S.; Russo, D.; et al. Gemcitabine-loaded PEGylated unilamellar liposomes vs. GEMZAR: Biodistribution, pharmacokinetic features and in vivo antitumor activity. J. Control. Release 2010, 144, 144-150.

165. Pattillo, C.B.; Sari-Sarraf, F.; Nallamothu, R.; Moore, B.M.; Wood, G.C.; Kiani, M.F. Targeting of the antivascular drug combretastatin to irradiated tumors results in tumor growth delay. Pharm. Res. 2005, 22, 1117-1120.

166. Mori, A.; Kennel, S.J.; van Borssum Waalkes, M.; Scherphof, G.L.; Huang, L. Characterization of organ-specific immunoliposomes for delivery of 3',5'-O-dipalmitoyl-5-fluoro-2'-deoxyuridine in a mouse lung-metastasis model. Cancer Chemother. Pharmacol. 1995, 35, 447-456.

167. Talbott, C.M.; Vorobyov, I.; Borchman, D.; Taylor, K.G.; DuPre, D.B.; Yappert, M.C. Conformational studies of sphingolipids by NMR spectroscopy. II. Sphingomyelin. Biochim. Biophys. Acta 2000, 1467, 326-337.

168. Allen, T.M.; Mumbengegwi, D.R.; Charrois, G.J. Anti-CD19-targeted liposomal doxorubicin improves the therapeutic efficacy in murine B-cell lymphoma and ameliorates the toxicity of liposomes with varying drug release rates. Clin. Cancer Res. 2005, 11, 3567-3573.

169. Working, P.K.; Dayan, A.D. Pharmacological-toxicological expert report. CAELYX. (Stealth liposomal doxorubicin HCl). Hum. Exp. Toxicol. 1996, 15, 751-785.

170. Hong, R.L.; Huang, C.J.; Tseng, Y.L.; Pang, V.F.; Chen, S.T.; Liu, J.J.; Chang, F.H. Direct comparison of liposomal doxorubicin with or without polyethylene glycol coating in C-26 tumor-bearing mice: Is surface coating with polyethylene glycol beneficial? Clin. Cancer Res. 1999, 5, 3645-3652.

171. Gabizon, A.; Martin, F. Polyethylene glycol-coated (pegylated) liposomal doxorubicin. Rationale for use in solid tumours. Drugs 1997, 54, 15-21.

172. Gabizon, A.; Shmeeda, H.; Barenholz, Y. Pharmacokinetics of pegylated liposomal Doxorubicin: Review of animal and human studies. Clin. Pharmacokinet. 2003, 42, 419-436.

173. Working, P.K.; Newman, M.S.; Sullivan, T.; Yarrington, J. Reduction of the cardiotoxicity of doxorubicin in rabbits and dogs by encapsulation in long-circulating, pegylated liposomes. J. Pharmacol. Exp. Ther. 1999, 289, 1128-1133.

174. Jain, R.K.; Stylianopoulos, T. Delivering nanomedicine to solid tumors. Nat. Rev. Clin. Oncol. 2010, 7, 653-664.

175. Minchinton, A.I.; Tannock, I.F. Drug penetration in solid tumours. Nat. Rev. Cancer 2006, 6, 583-592.

176. Baxter, L.T.; Zhu, H.; Mackensen, D.G.; Butler, W.F.; Jain, R.K. Biodistribution of monoclonal antibodies: Scale-up from mouse to human using a physiologically based pharmacokinetic model. Cancer Res. 1995, 55, 4611-4622.

177. Mager, D.E.; Jusko, W.J. Development of translational pharmacokinetic-pharmacodynamic models. Clin. Pharmacol. Ther. 2008, 83, 909-912.

178. El-Kareh, A.W.; Secomb, T.W. A mathematical model for comparison of bolus injection, continuous infusion, and liposomal delivery of doxorubicin to tumor cells. Neoplasia 2000, 2, 325-338.

179. Gianni, L.; Kearns, C.M.; Giani, A.; Capri, G.; Vigano, L.; Lacatelli, A.; Bonadonna, G.; Egorin, M.J. Nonlinear pharmacokinetics and metabolism of paclitaxel and its pharmacokinetic/pharmacodynamic relationships in humans. J. Clin. Oncol. 1995, 13, 180-190. 
180. Griffon-Etienne, G.; Boucher, Y.; Brekken, C.; Suit, H.D.; Jain, R.K. Taxane-induced apoptosis decompresses blood vessels and lowers interstitial fluid pressure in solid tumors: Clinical implications. Cancer Res. 1999, 59, 3776-3782.

181. Lu, D.; Wientjes, M.G.; Lu, Z.; Au, J.L. Tumor priming enhances delivery and efficacy of nanomedicines. J. Pharmacol. Exp. Ther. 2007, 322, 80-88.

182. Aroui, S.; Brahim, S.; de Waard, M.; Breard, J.; Kenani, A. Efficient induction of apoptosis by doxorubicin coupled to cell-penetrating peptides compared to unconjugated doxorubicin in the human breast cancer cell line MDA-MB 231. Cancer Lett. 2009, 285, 28-38.

183. Desai, N.; Trieu, V.; Yao, Z.; Louie, L.; Ci, S.; Yang, A.; Tao, C.; De, T.; Beals, B.; Dykes, D.; et al. Increased antitumor activity, intratumor paclitaxel concentrations, and endothelial cell transport of cremophor-free, albumin-bound paclitaxel, ABI-007, compared with cremophor-based paclitaxel. Clin. Cancer Res. 2006, 12, 1317-1324.

184. Milas, L.; Hunter, N.R.; Kurdoglu, B.; Mason, K.A.; Meyn, R.E.; Stephens, L.C.; Peters, L.J. Kinetics of mitotic arrest and apoptosis in murine mammary and ovarian tumors treated with taxol. Cancer Chemother. Pharmacol. 1995, 35, 297-303.

185. Sparreboom, A.; van Tellingen, O.; Nooijen, W.J.; Beijnen, J.H. Nonlinear pharmacokinetics of paclitaxel in mice results from the pharmaceutical vehicle Cremophor EL. Cancer Res. 1996, 56, 2112-2115.

186. Ah-See, M.L.; Makris, A.; Taylor, N.J.; Harrison, M.; Richman, P.I.; Burcombe, R.J.; Stirling, J.J.; d'Arcy, J.A.; Collins, D.J.; Pittam, M.R.; et al. Early changes in functional dynamic magnetic resonance imaging predict for pathologic response to neoadjuvant chemotherapy in primary breast cancer. Clin. Cancer Res. 2008, 14, 6580-6589.

187. Baek, H.M.; Yu, H.J.; Chen, J.H.; Nalcioglu, O.; Su, M.Y. Quantitative correlation between ${ }^{1} \mathrm{H}$ MRS and dynamic contrast-enhanced MRI of human breast cancer. Magn. Reson. Imaging 2008, 26, 523-531.

188. Yankeelov, T.E.; Lepage, M.; Chakravarthy, A.; Broome, E.E.; Niermann, K.J.; Kelley, M.C.; Meszoely, I.; Mayer, I.A.; Herman, C.R.; McManus, K.; et al. Integration of quantitative DCE-MRI and ADC mapping to monitor treatment response in human breast cancer: Initial results. Magn. Reson. Imaging 2007, 25, 1-13.

189. Eytan, G.D.; Kuchel, P.W. Mechanism of action of P-glycoprotein in relation to passive membrane permeation. Int. Rev. Cytol. 1999, 190, 175-250.

190. Baxter, L.T.; Zhu, H.; Mackensen, D.G.; Jain, R.K. Physiologically based pharmacokinetic model for specific and nonspecific monoclonal antibodies and fragments in normal tissues and human tumor xenografts in nude mice. Cancer Res. 1994, 54, 1517-1528.

191. Stewart, D.J. Making and using DNA microarrays: A short course at Cold Spring Harbor Laboratory. Genome Res. 2000, 10, 1-3.

(C) 2014 by the authors; licensee MDPI, Basel, Switzerland. This article is an open access article distributed under the terms and conditions of the Creative Commons Attribution license (http://creativecommons.org/licenses/by/3.0/). 